School of Economics Australian School of Business UNSW Sydney NSW 2052 Australia

http://www.economics.unsw.edu.au

\title{
Engineering Trust - Reciprocity in the Production of Reputation Information
}

\author{
Gary Bolton, Ben Greiner, and Axel Ockenfels
}

School of Economics Discussion Paper: 2009/02

The views expressed in this paper are those of the authors and do not necessarily reflect those of the School of Economic at UNSW. 


\title{
ENGINEERING TRUST
}

\author{
- Reciprocity in the Production of Reputation Information -
}

\author{
GARY BOLTON, BEN GREINER, AND AXEL OCKENFELS
}

5 March 2009

\begin{abstract}
Reciprocal feedback distorts the production and content of reputation information, hampering trust and trade efficiency. Data from eBay and other sources combined with laboratory data provide a robust picture of how reciprocity can be guided by changes in the way feedback information flows through the system, leading to more accurate reputation information, more trust and more efficient trade.
\end{abstract}

Keywords: market design, reputation, trust, reciprocity, eBay

JEL classification: C73, C9, D02, L14

Financial support from the German Science Foundation (DFG) and U.S. National Science Foundation (NSF) is gratefully acknowledged. We thank Brian Burke, Debbie Hofmeyr, Leland Peterson and the rest of eBay's Trust\&Safety team for their cooperation in this research project and for sharing data with us, and Ido Erev, Al Roth and seminar participants at Berlin, Copenhagen, Graz, Harvard, Indiana, Max Planck Jena, Michigan, Royal Holloway London, Nürnberg, Santa Barbara, and Sydney for helpful comments. We are indebted to Felix Lamouroux, Karin Ruetz, and Dietmar Ilsen for excellent research assistance and help with the collection of data.

Bolton. Pennsylvania State University, Smeal College of Business, University Park, PA 16802, Tel: 1 (814) 865 0611, Fax: 1 (814) 865 6284, e-mail: gbolton at psu.edu.

Greiner. University of New South Wales, School of Economics, Sydney, NSW 2052, Australia, Tel: +61 293859701 , Fax: +6129313 6337, e-mail: bgreiner at unsw.edu.au.

Ockenfels. University of Cologne, Department of Economics, Albertus-Magnus-Platz, D-50923 Köln, Germany, Tel: +49/221/470-5761, Fax: +49/221/470-5068, e-mail: ockenfels at uni-koeln.de. 


\section{Introduction}

This paper reports on the repair of an Internet market trust mechanism. While all markets require some minimum amount of trust (Akerlof, 1970), it is a particular challenge for Internet markets, where trading is typically anonymous, geographically dispersed, and executed sequentially. To incentivize trustworthiness, Internet markets commonly employ reputation-based 'feedback systems' that enable traders to publicly post information about past transaction partners. Online markets with this kind of feedback system include eBay.com, Amazon.com, and RentACoder.com, among many others. For these markets, feedback systems with their large databases of transaction histories are a core asset, crucial for market efficiency and user loyalty.

Engineering studies examine institutional design problems at a fine-grained level. They constitute a unique kind of testing ground for existing concepts and for identifying new questions for economic theory. ${ }^{1}$ In the present case, economic theory implies that a reputation system that elicits accurate and complete feedback information can promote trust and cooperation among selfish traders even in such adverse environments as online market platforms. ${ }^{2}$ So there is theoretical reason to believe that a properly designed feedback system can effectively facilitate trade. At the same time, the nature of the problem takes us further down the causation chain than received theory presently goes, to gaming in the production of reputation information. In essence, reputation builders retaliate in-kind for a negative review, thereby inhibiting the provision of negative reviews in the first place. The resulting bias in reputation information then works its way up the chain, ultimately diminishing market efficiency. Other reputation-based systems are open to similar retaliation (ex., financial rating services, employee job assessments, word-of-mouth about colleagues), so the phenomenon likely has a life beyond Internet markets.

Below we present new data from the eBay marketplace exhibiting a strong and general reciprocal pattern in the content, timing and quantity of reputation information (Section II). It turns out that the institutional trigger for this behavior is the timing and posting rules governing feedback giving. The natural approach to fixing the problem then is to change these rules to diminish reciprocal behavior. Doing so involved two large uncertainties. First, it was not clear how responsive the

\footnotetext{
${ }^{1}$ Roth (2002) argues the need for a literature "to further the design and maintenance of markets and other economic institutions [p. 1341]" and provides examples of how this literature can help shape new questions in economic theory. To date, the market design literature has focused mostly on allocation mechanisms such as auctions and matching. Roth (2008) reviews the literature on matching markets, Milgrom (2004) the literature on auction markets, and Ockenfels, Reiley, and Sadrieh (2006) the literature specific to Internet auctions.

${ }^{2}$ See, for example, Wilson (1985) and, for the literature specific to feedback systems, Dellarocas (2006).
} 
system would be: In order to influence trade, the new system need evoke subtle, strategically motivated changes in the behavior of the traders, at multiple points, as the information flows through the market. Second, changing the feedback rules risks undesirable side effects, as reciprocal feedback has positive, as well as negative consequences. Most critically, reciprocity appears important to getting (legitimately) satisfactory trades reported; eliminating this kind of reciprocity might lead to a system that over reports, rather than under reports, negative outcomes.

With these considerations in mind, our study examines two alternative proposals (also Section II). ${ }^{3}$ Analyzing data from other Internet markets that have feedback systems with features similar to those proposed suffices to answer some of our questions (Section III). But not all of them. There are behavioral and institutional differences across the markets we examine and this leaves substantial ambiguity; one proposal, in particular, has major features not shared with any existing market. Also, we lack field data on the underlying cost and preference parameters in the markets, and so cannot easily measure how feedback systems affect market efficiency. To narrow the uncertainty, we complement the field data with a test bed experiment crafted to capture the theoretically relevant aspects of behavior and institutional changes (Section IV). ${ }^{4}$

In combination, the field and lab data provide a robust picture of how reciprocity can be guided through the design of information channels. We will see that more accurate information sets off an endogenous shift in the market, leading to greater trust and trustworthiness, and more efficient trade. Our analysis guided eBay in its decision to change the reputation system. We present preliminary data on how the new field system performs (Section V). We conclude with lessons for market design and future theory building (Section VI).

\section{The feedback problem and two proposals to fix it}

In this section we first review eBay's conventional feedback system (Subsection II.1). We then examine evidence, from new data as well as from the work of other researchers, for a reciprocal pattern in feedback giving and for the role of the rules that govern feedback giving (Subsection II.2).

\footnotetext{
${ }^{3}$ A number of others proposals were considered but discarded relatively quickly in favor of the two discussed here.

4 Test bed experiments to get insight into how a market redesign will work has been done in relation to allocation mechanisms; for example, Grether, Isaac, and Plott (1981), Kagel and Roth (2000), Chen (2005), Kwasnica, Ledyard, Porter, and DeMartini (2005), Chen and Sönmez (2006) and Brunner, Goeree, Holt, and Ledyard (forthcoming).
} 
An important point will be that reciprocal behavior has good as well as bad consequences for the system. We then discuss two proposals put forward to mitigate the problem (Subsection II.3). ${ }^{5}$

\section{II.1 EBay's conventional feedback system}

EBay facilitates trade in the form of auctions and posted offers in over thirty countries. ${ }^{6}$ After each eBay transaction, both the buyer and the seller are invited to give feedback on each other. Until spring 2007, when eBay changed the system, only "conventional" feedback could be left. In the conventional feedback system, a trader can rate a transaction positive, neutral, or negative (along with a text comment). Submitted feedback is immediately posted and available to all traders. Conventional feedback ratings can be removed from the site only by court ruling, or if the buyer did not pay, or if both transaction partners mutually agree to withdrawal. ${ }^{7}$

The most common summary measure of an eBay trader's feedback history is the feedback score, equal to the difference between the number of positive and negative feedbacks from unique eBay traders (neutral scores are ignored). Each trader's feedback score is provided on the site. An important advantage of the feedback score is that it incorporates a reliability measure (experience) in the measure of trustworthiness. The feedback score is also the most commonly used measure of feedback history in research analyses of eBay data. ${ }^{8}$

\section{II.2 Reciprocal feedback}

Feedback information is largely a public good, helping other traders to manage the risks involved in trusting unknown transaction partners. Yet our data finds that about $70 \%$ of the traders

\footnotetext{
5 That said, many (but not all) studies find that feedback has positive value for traders as indicated by positive correlations between the feedback score of a seller and the revenue and the probability of sale. See, for example, Bajari and Hortaçsu (2003, 2004), Ba and Pavlou (2002), Cabral and Hortaçsu (forthcoming), Dellarocas (2004), Dewan and Hsu (2001), Eaton (2007), Ederington and Dewally (2006), Houser and Wooders (2005), Jin and Kato (forthcoming), Kalyanam and McIntyre (2001), Livingston (2005), Livingston and Evans (2004), Lucking-Reiley, Bryan, Prasad, and Reeves (2007), McDonald and Slawson (2002), Melnik and Alm (2002), Ockenfels (2003), Resnick and Zeckhauser (2002), and Resnick, Zeckhauser, Swanson, and Lockwood (2006). See Ba and Pavlou (2002), Bolton, Katok, and Ockenfels (2004, 2005), and Bolton and Ockenfels (forthcoming) for laboratory evidence.

${ }^{6}$ In 2006, 82 million users bought or sold $\$ 52$ billion in goods on eBay platforms.

${ }^{7}$ EBay's old feedback system was the product of an 11 year evolutionary process. In its first version, introduced in 1996 , feedback was not bound to mutual transactions: every community member could give an opinion about every other community member. In 1999/2000 the ability to submit non-transaction related feedback was removed. The percentage of positive feedback was introduced in 2003, and in 2004 the procedure of mutual feedback withdrawal was added. Since 2005, feedback submitted by eBay users leaving the platform shortly thereafter or not participating in issue resolution processes' is made ineffective, and members who want to leave neutral or negative feedback must go through a tutorial before being able to do so. Since spring 2007 a new system was introduced, as described in Section V. In 2008, again new features were implemented, which are analyzed in Bolton, Greiner and Ockenfels (2009).

8 Another common measure is the 'percentage positive' equal to the share of positive and negative feedbacks that is positive. For our data, which measure is used seems to make little difference; we mostly report results using the feedback score.
} 
leave feedback (a number consistent with previous research). ${ }^{9}$ In this subsection, we examine evidence that reciprocity plays a role in the giving as well as timing and content of eBay feedback. In the following, the null hypothesis is always that feedback is given independently, whereas the alternative hypothesis states that feedback is given conditionally, following a reciprocal pattern. ${ }^{10}$ The analysis is based on 700,000 completed eBay transactions taken from seven countries and six categories in 2006/07 (Dataset 1, Appendix A.1).

Feedback giving. If feedback were given independently among trading partners, one would expect the percentage of time both partners give feedback to be about $70 \% * 70 \%=49 \%$. Yet mutual feedback is given much more often, about $64 \%$ of the time. The reason is evident from the top rows of Table 1: Both buyers and sellers are more likely to provide feedback when the transaction partner has given feedback first. The effect is stronger for sellers than for buyers; when a buyer gives feedback, the seller leaves feedback $87.4 \%$ of the time, versus $51.4 \%$ when the buyer does not leave feedback (in a moment we will see that sellers sometimes have an incentive to wait). A common buying experience on eBay, after a transaction has gone smoothly, is to receive a note from the seller saying he gave you positive feedback and asking you to provide feedback, or saying that he would give you feedback once you left feedback on him (playing or initiating a kind of "trust game"). Indeed, the evidence suggests that this kind of reciprocal behavior is an effective tactic for reputation building.

Feedback content. Also observe from Table 1 that there is a high positive correlation between buyer and seller feedback within all countries sampled. There are probably a number of reasons for this; for example, a problematic transaction might leave both sides dissatisfied. But Table 1 also provides a first hint that reciprocity in feedback content has a strategic element: If feedback is given independently, the correlation between seller and buyer content, as measured by tau, should be about the same when the seller gives second as when the seller gives first. In fact, the correlation is about twice as high when the seller gives second. The pattern is similar across countries.

\footnotetext{
9 The number varies somewhat across categories and countries; see Table 8 in Appendix A.1. Resnick and Zeckhauser (2002) found that buyers gave feedback in 51.7\% of the cases, and sellers in $60.6 \%$. Cabral and Hortaçsu (forthcoming) report a feedback frequency from buyer to seller in 2002/03 of 40.7\% in 1,053 auctions of coins, notebooks and Beanie Babies. In their 2002 dataset of 51,062 completed rare coin auctions on eBay, Dellarocas and Wood (2008) observed feedback frequencies of $67.8 \%$ for buyers and $77.5 \%$ for sellers.

10 Others recognized the strategic interdependency of feedback before, including Resnick, Zeckhauser, Friedman, and Kuwabara (2000), Resnick and Zeckhauser (2002), and, more recently, Klein, Lambertz, Spagnolo, and Stahl (2007) and Dellarocas and Wood (2008). In this and parts of the following sections, we complement this literature from an engineering perspective, combining data sets that follow a large set of eBay transactions from their posting until the end of their feedback period (both for the time before and after the institutional change discussed here), data sets from various eBay platforms in four continents differing in their feedback institutions, as well as data sets from reputation systems of other Internet market platforms, and from markets implemented in the laboratory - as further discussed below and in the Appendix.
} 


\begin{tabular}{lcc} 
TABLE 1: FEEDBACK GIVING AND CONTENT, CONDITIONAL PROBABILITIES AND CORRELATIONS \\
\hline \hline Feedback giving probability & Partner did not yet give FB & Partner gave FB already \\
\hline Buyer & $68.4 \%$ & $74.1 \%$ \\
Seller & $51.4 \%$ & $87.4 \%$ \\
\hline \hline
\end{tabular}

Kendall's tau correlations between seller's and buyer's feedback

\begin{tabular}{|c|c|c|c|c|c|c|c|c|}
\hline \multirow[b]{4}{*}{ Country } & \multicolumn{6}{|c|}{ FB content correlation } & \multirow{3}{*}{\multicolumn{2}{|c|}{$\begin{array}{l}\text { FB giving } \\
\text { correlation }\end{array}$}} \\
\hline & \multirow{2}{*}{\multicolumn{2}{|c|}{ All cases }} & \multirow{2}{*}{\multicolumn{2}{|c|}{$\begin{array}{l}\text { Buyer gave } \\
\text { FB second }\end{array}$}} & \multirow{2}{*}{\multicolumn{2}{|c|}{$\begin{array}{l}\text { Seller gave } \\
\text { FB second }\end{array}$}} & & \\
\hline & & & & & & & & \\
\hline & $\mathrm{N}$ & tau & $\mathrm{N}$ & Tau & $\mathrm{N}$ & tau & $\mathrm{N}$ & tau \\
\hline All & 458,249 & 0.710 & 139,772 & 0.348 & 318,477 & 0.884 & 725,735 & 0.693 \\
\hline Australia & 20,928 & 0.746 & 6,040 & 0.340 & 14,888 & 0.928 & 31,990 & 0.752 \\
\hline Belgium & 8,474 & 0.724 & 3,097 & 0.464 & 5,377 & 0.880 & 12,301 & 0.684 \\
\hline France & 24,933 & 0.727 & 8,095 & 0.423 & 16,838 & 0.883 & 39,104 & 0.703 \\
\hline Germany & 133,957 & 0.656 & 45,836 & 0.331 & 88,121 & 0.840 & 192,565 & 0.644 \\
\hline Poland & 457 & 1.000 & 172 & - & 285 & 1.000 & 1,134 & 0.783 \\
\hline U.K. & 93,266 & 0.694 & 31,316 & 0.379 & 61,950 & 0.875 & 143,877 & 0.692 \\
\hline U.S. & 176,009 & 0.746 & 45,133 & 0.313 & 130,876 & 0.911 & 302,213 & 0.701 \\
\hline
\end{tabular}

Notes: Observations where feedback was eventually withdrawn are not included in correlations. In the cell marked with "“-", the standard deviation is zero. All other correlations are highly significant.

Feedback timing. If feedback timing were independent among trading partners, one would expect the timing of buyer and seller feedback to be uncorrelated with content. But this is not the case: Figure 1 shows scatter plots for the distribution of feedback timing for those transactions where both traders actually left feedback. The green dots represent the timing of mutually positive feedback. More than $70 \%$ of all these observations are located below the 45 degree line, indicating that in most cases the seller gives feedback after the buyer. The red dots visualize observations of mutually problematic feedback. Here, the sellers' feedback is given second in more than $85 \%$ of the cases. Moreover, mutually problematic feedback is much more heavily clustered alongside the 45 degree line as compared to the case of mutually positive feedback. The tightness and sequence in timing suggests that sellers quickly 'retaliate' negative feedback. ${ }^{11}$

Seller retaliation also explains why more than $70 \%$ of cases in which the buyer gives problematic feedback and the seller gives positive feedback (blue dots in Figure 1), involve the buyer giving second; not doing so would involve a high risk of being retaliated. Observations in which only the seller gives problematic feedback (yellow dots) are rare and have their mass below the 45-degree line.

\footnotetext{
11 The consequences of market timing are a major theme in market design; see, for example, Niederle and Roth (2009) and references therein.
} 


\section{FIGURE 1: CONTENT AND TIMING OF MUTUAL FEEDBACK ON EBAY}

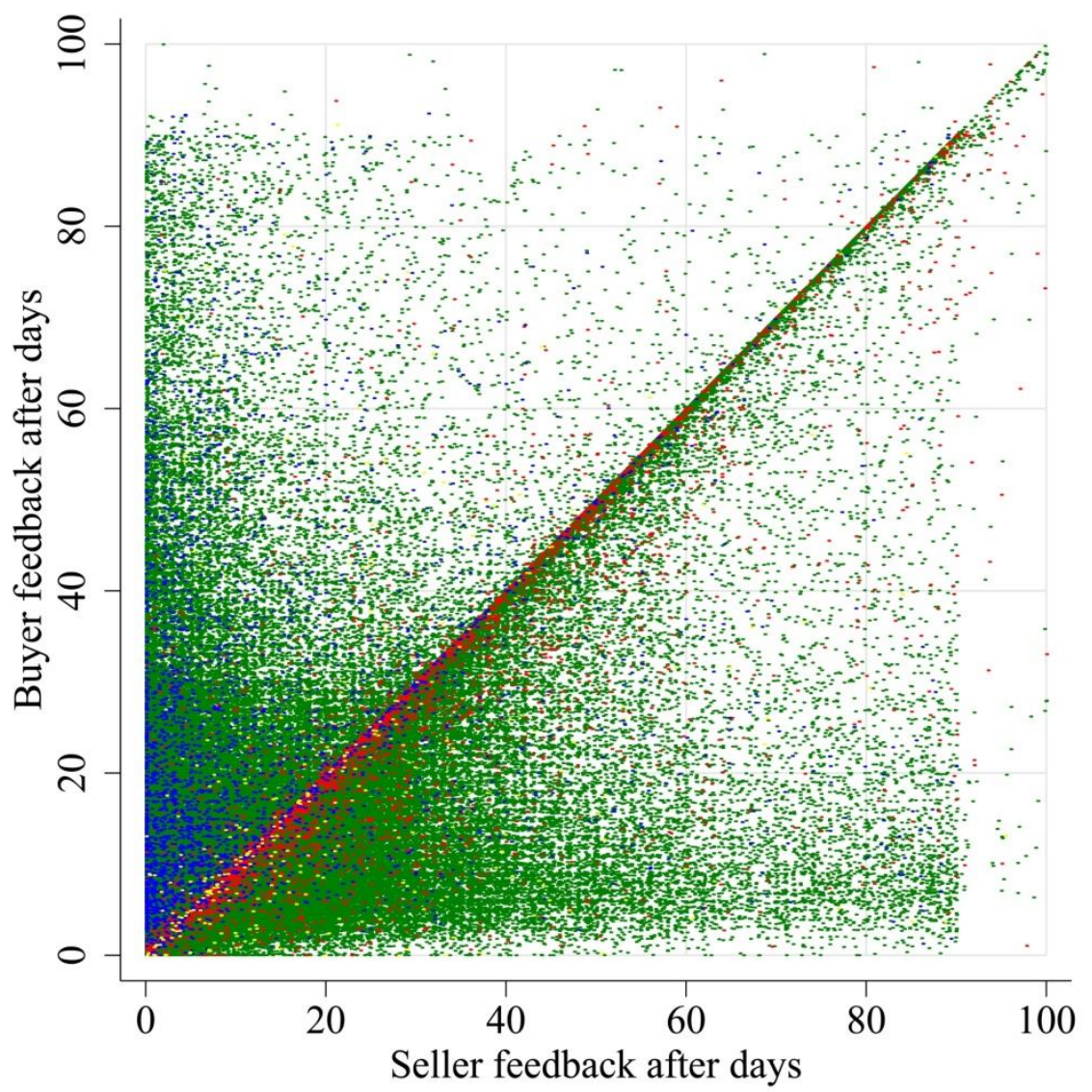

Mutually positive feedback $(\mathrm{N}=451,227)$

Only buyer left problematic feedback $(\mathrm{N}=2,884)$

Mutually problematic feedback $(\mathrm{N}=5,279)$

Only seller left problematic feedback $(\mathrm{N}=357)$

Notes: The scatter plot reports about 460,000 observations where both transaction partners gave feedback. 'Problematic' feedback includes neutral or withdrawn feedback.

Why do sellers retaliate negative feedback? Existing theory and laboratory studies on reputation building, while not developed in the context of the production of reputation information, suggest that there are multiple strategic and social motives at work ${ }^{12}$ (and these dovetail well with anecdotal and survey evidence that we have collected). Some retaliation is probably driven by social preferences or emotional arousal, e.g., when a buyer's negative feedback is deemed undeserved by the seller. Retaliating negative feedback may also help to deter negative feedback in the future, because retaliation is viewable by buyers in a seller's feedback history. Also, giving a negative feedback increases the probability that the opponent will agree to mutually withdraw the feedback.

\footnotetext{
${ }^{12}$ See, e.g., Kreps and Wilson (1982), Milgrom, North, and Weingast (1990), Greif (1989), Camerer and Weigelt (1988), Neral and Ochs (1992), Brandts and Figueras (2003), and Bolton et al. (2004) for the strategic role in reciprocity, and Fehr and Gächter (2000), as well as the surveys in Cooper and Kagel (forthcoming) and Camerer (2003) for the social aspect in reciprocity.
} 
In fact, of the cases where a seller responds to a negative with a negative feedback, about $27 \%$ are later withdrawn. Yet if the seller gives negative feedback before the buyer's negative is posted (and so does not retaliate), the percentage of mutual withdrawal is only about $3 \%$, suggesting that nonretaliatory negative feedback is driven by different motives than retaliatory negative feedback.

\section{3 Two alternative redesign proposals}

Any institutional change in a running market must respect certain path dependencies. This is particularly true for reputation systems, which by their nature connect the past with the future. For this reason, the redesign proposals we consider maintain (in some form) the conventional ratings of the existing system, allowing traders to basically maintain their reputation built before the change. At the same time, each proposal attacks one or the other of two features that appear to facilitate reciprocal behavior, either the open, sequential posting that allows a trading partner to react to the feedback information, or the symmetric nature of the ratings that allows sellers to retaliate buyers.

Proposal 1. Make conventional feedback blind. To do so, conventional feedback would be given simultaneously in the sense that traders cannot see the opponent's feedback before leaving one's own feedback. Traders cannot condition their feedback on the feedback posted by a transaction partner, thereby excluding sequential reciprocity and strategic timing, making seller retaliation more difficult. The conjecture is that this will lead to more accurate feedback. ${ }^{13}$

A major risk with a blind system concerns whether it will diminish the frequency of feedback giving, particularly with regard to mutually satisfactory transactions. Because trading partners effectively give feedback simultaneously, giving a positive feedback could not be used to induce a trading partner to do the same.

Proposal 2. Add a detailed seller rating (DSR) system to supplement conventional feedback. In principle, a onesided system in which only the buyer gives feedback is the surest way to end seller retaliation. ${ }^{14}$ But while there is more scope for moral hazard on the seller side than on the buyer side in eBay's marketplace, there is some room for buyer moral hazard as well. ${ }^{15}$ Moreover, gaining positive

\footnotetext{
${ }^{13}$ A blind system of this sort has been suggested by Güth, Mengel, and Ockenfels (2007), Reichling (2004) and Klein et al. (2007), among others.

${ }^{14}$ A system of this sort has been proposed by Chwelos and Dhar (2007), among others. These systems share elements with a system that strictly separates feedback earned as a seller and feedback earned as a buyer, which is discussed and experimentally analyzed in Bolton et al. (2009).

15 While there is little formal evidence at this point for buyer moral hazard on eBay, we collected considerable evidence in our surveys with eBay traders conducted jointly with eBay, anecdotal evidence from eBay's online feedback forum and
} 
feedback as a buyer appears to be an important step for many traders in their transition to a successful seller. For these reasons, the proposal was to create a detailed seller rating system to supplement the conventional feedback system: Conventional feedback would be published immediately, as usual, but the buyer, and only the buyer, can leave additional feedback on the seller under blind conditions so that the seller cannot reciprocate them. ${ }^{16}$

A major risk is that the conventional and DSR feedback given to sellers might diverge. Unhappy buyers might give positive conventional feedback to avoid seller retaliation, and then be truthful with the (blind) DSR score. This could cause the feedback system scoring to have a new kind of credibility problem with traders.

To summarize this section, people tend to reciprocate the feedback they are given, like with like. The timing and posting rules governing feedback giving in eBay's conventional feedback system facilitate reciprocity and strategic responses to reciprocity. This has both negative and positive consequences for the system. On the negative side, reciprocity distorts the production and content of feedback information in individual interactions (Section II.2). On the aggregate level, these prospects of positive reciprocal and negative retaliatory feedback may lead to 'overly' positive feedback, hampering the informativeness of the system. The fact that from all 742,829 eBay users in Dataset 1 who received at least one feedback, 67\% have a percentage positive of $100 \%$, and $80.5 \%$ have a percentage positive of greater than 99\% provides suggestive support for the bias. The observation is in line with other eBay research suggesting that feedback is 'overly' positive, ${ }^{17}$ and also with a general tendency for lenient and compressed performance ratings, as discussed for instance in the literature on the "leniency bias" and "centrality bias" in personnel economics (Bretz, Milkovich, and Read, 1992; Prendergast and Topel, 1993; Prendergast, 1999). On the positive side, reciprocity

from eBay seller conferences. There are basically four themes: 1) The buyer purchases the item, but never sends the payment, which incurs time costs on the seller as well as fees to eBay. 2) The buyer has unsubstantiated complains about the item. 3) The buyer blackmails the seller regarding feedback. Stories exist where the buyer asked for a second item for free, threatening negative feedback if this wish would not be fulfilled. 4) After two months the buyer asks the credit card provider to retrieve the payment (eBay's payment service PayPal does not provide support in these cases).

16 Another advantage is that we can fine tune the scaling of the new ratings without disrupting the 3-point conventional ratings; the latter would create a number of path dependency problems. Research in psychology suggests that Likert scaling of 5 or 7 points is optimal (e.g., Nunnally, 1978; and more recently Muniz, Garcia-Cueto, and Lozano, 2005). Additionally, several studies have found that users generally prefer to rate on more categories rather than submitting just one general rating (e.g., Oppenheim, 2000). The specific method for posting detailed seller ratings is best understood in the context of a number of practical considerations and is described at the beginning of Section $\mathrm{V}$.

${ }^{17}$ Dellarocas and Wood (2008) examine the information hidden in the cases where feedback is not given. They estimate that buyers are at least mildly dissatisfied in about $21 \%$ of all eBay transactions, far higher than the levels suggested by the reported feedback. Similarly, in a controlled field experiment conducted on eBay with experienced eBay traders, Bolton and Ockenfels (2008) found that sellers, who did not share the gains from trade in a fair manner, received significantly less feedback than sellers who offered buyers a fair outcome. 
appears to be an important motivator in getting mutually satisfactory trades reported. The blind conventional feedback proposal alters the sequential, open feedback rule, while the DSR proposal creates an asymmetry in the system so that sellers do not have the opportunity to retaliate the more detailed rating. Each has risks of generating adverse side effects concerning, respectively, the amount or consistency of feedback given.

\section{Evidence from other Internet markets}

As a first step in evaluating the two proposals (Section II.3), we searched for and examined systems involving blind and one-sided feedback in other Internet markets.

The first evidence comes from eBay's own market in Brazil. MercadoLivre began in 1999 as an independent market, eBay-like in its objective but with some unique trading procedures. EBay bought the market in 2001 and decided to keep some procedures, including a blind feedback system. ${ }^{18}$ MercadoLivre reveals submitted feedback after a 21-day "blind period" that starts upon completion of the transaction. No feedback can be given after the blind period has lapsed.

TABLE 2: FEEDBACK FREQUENCY, CONTENT AND CORRELATION ON MERCADO LIVRE AND EBAY CHINA COMPARED TO OTHER EBAY PLATFORMS

\begin{tabular}{|c|c|c|c|c|c|c|c|}
\hline & \multirow[b]{2}{*}{$\mathrm{N}$} & \multicolumn{2}{|c|}{$\begin{array}{l}\text { Feedback } \\
\text { frequency }\end{array}$} & \multicolumn{2}{|c|}{$\begin{array}{c}\text { problematic FB } \\
\text { given by }\end{array}$} & \multirow{2}{*}{$\begin{array}{l}\text { FB Content } \\
\text { Correlation } \\
\text { Kendall's tau }\end{array}$} & \multirow{2}{*}{$\begin{array}{c}\text { FB Giving } \\
\text { Correlation } \\
\text { Kendall's tau }\end{array}$} \\
\hline & & Buyer & Seller & Buyer & Seller & & \\
\hline eBay U.S. & 10,169 & $74.8 \%$ & $76.7 \%$ & $1.4 \%$ & $1.2 \%$ & 0.720 & 0.595 \\
\hline eBay Germany & 14,297 & $77.3 \%$ & $76.9 \%$ & $1.9 \%$ & $1.1 \%$ & 0.621 & 0.623 \\
\hline eBay China & 2,011 & $9.3 \%$ & $19.7 \%$ & $5.0 \%$ & $6.7 \%$ & 0.576 & 0.652 \\
\hline$\ldots$ verified buyers & 1,062 & $15.0 \%$ & $13.6 \%$ & $5,0 \%$ & $4.9 \%$ & 0.576 & 0.682 \\
\hline ... unverified buyers & 949 & $3.1 \%$ & $3.6 \%$ & & $14.7 \%$ & & 0.460 \\
\hline MercadoLivre Brazil & 1,958 & $71.1 \%$ & $87.9 \%$ & $18.7 \%$ & $29.2 \%$ & 0.785 & 0.175 \\
\hline
\end{tabular}

Note: All correlations are highly significant.

Table 2 shows feedback statistics based on a total of 24,435 completed transactions in Dataset 3 , which was specifically compiled to compare feedback behavior in eBay's conventional feedback system to other eBay sites like MercadoLivre and eBay China, which we will come back to in the next section (see Appendix A.3 for a detailed description of this dataset). ${ }^{19}$ Observe that the share of problematic (negative, neutral, and withdrawn) feedback given on MercadoLivre is multiple times

\footnotetext{
${ }^{18}$ Hortaçsu, Martínez-Jerez, and Douglas (2009) compare bidding behavior on different MercadoLivre sites and eBay.

${ }^{19}$ MercadoLivre posts only the day of feedback provision, but not the time, and also updates this date stamp when further verbal comments are left. For this reason we cannot provide information on whether buyer or seller left feedback first.
} 
higher than on other mature eBay platforms that do not employ a blind feedback system, strongly suggesting that blindness indeed affects the feedback distribution. Moreover, while the correlation of feedback content differs little from that in other markets (Column 5 in Table 2), the correlation of feedback giving is much lower in Brazil than in the U.S., Germany, or China (Column 6 in Table 2). That is, in those cases where both transaction partners leave feedback, the content in Brazil is as correlated as in the other countries, but the probability of two-way feedback giving is much smaller.

One worry with a blind system is that diminishing reciprocal opportunities might diminish the rate at which traders leave feedback. But on MercadoLivre there is no evidence that the blind system decreases participation; the feedback frequency of $70 \%$ for buyers is in line with what we observe in other countries, and with $87.9 \%$ sellers provide even more feedback.

Overall, the data seem to suggest that the blind system generates a more accurate, or at least a more dispersed reflection of trader satisfaction on both sides of the market. However, as with every comparison across markets, there are a number of potentially confounding effects complicating the comparison. We will discuss this issue at the end of the section, when we have presented the data from other field comparisons.

The RentACoder.com site enables software coders to bid for contracts offered by software buyers. RentACoder.com used to have a two-sided, open feedback system, similar to eBay, but switched to a blind system in April 2005. RentACoder's motive for the switch (as stated on its help page) is the potential threat of retaliatory feedback in an open system. The blind system allows buyers and coders to leave feedback on one another within a period of two weeks after completion of a project.

The RentACoder.com panel data (Dataset 4, see Appendix A.4) comprises 192,392 transactions. Unlike the MercadoLivre comparison, it allows for a within site comparison, keeping all institutions but the feedback system fixed, and allowing an analysis of the transition from an open to a blind system. The transition has no significant effect on average feedback content received by either buyers or sellers, although there is a weakly significant, small increase in the standard deviation of feedback received by buyers. ${ }^{20}$ There are, however, other effects indicative of diminishing reciprocity. First, as shown in Figure 2, the monthly correlation between feedback content sharply and significantly drops from an average of 0.62 in the 15 months before the change to 0.21 in the 21 months after the change. We also observe from Figure 2 (and backed by time series regressions

\footnotetext{
${ }^{20}$ Because of space limitations, we omit here the regressions of time series of monthly averages on constant, time trend and blindness dummy, which confirm the observation.
} 
controlling for trends), that coders get significantly less feedback after introduction of blind feedback, while buyers get a small but significant increase. Overall, the patterns of reduced interdependencies of feedback giving and content seem to suggest that feedback might be more informative. At the same time, however, there is some evidence from RentACoder.com that feedback frequency may be negatively affected by a blind system.

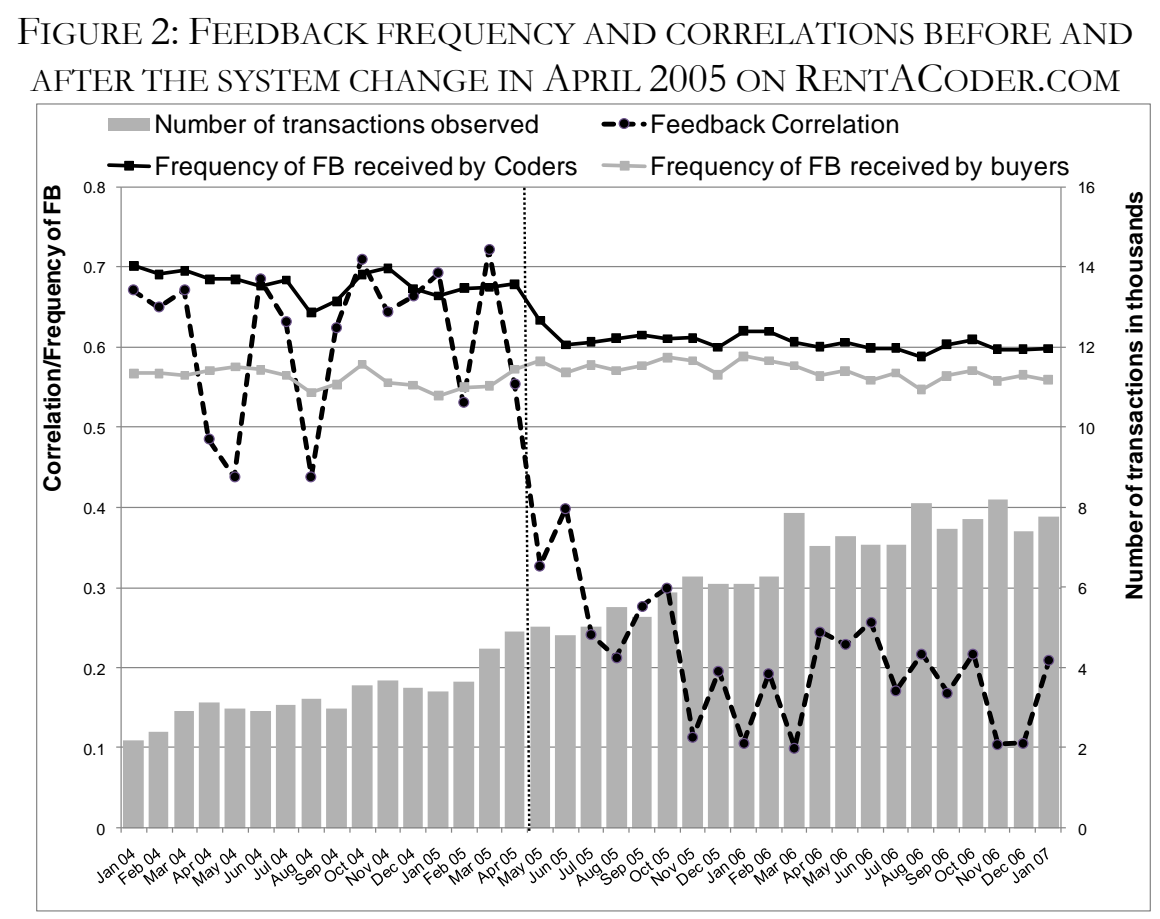

The hypothesis that diminishing reciprocity diminishes feedback giving finds further support by looking at systems with one-way feedback characteristics. The first evidence comes from a kind of within platform comparison on the Chinese eBay site, where there is a large proportion of so-called "unverified buyers." Feedback given by unverified buyers does not count towards the seller's reputation. From a reciprocity perspective, giving feedback to unverified buyers is not unlike giving one-sided feedback. Table 2 shows frequency and content of feedback for verified and unverified buyers. We observe that verified buyers receive and give about five times as much feedback as unverified buyers $\left(\chi^{2}=82.6, \mathrm{p}<0.001\right)$ and that feedback giving is much more correlated with verified buyers (the correlation coefficients are 0.460 versus 0.682$).^{21}$

\footnotetext{
${ }^{21}$ Moreover, unverified buyers receive a neutral or negative feedback with probability $14.7 \%$ in our sample, whereas verified buyers only receive a negative feedback with probability $4.9 \%$ (due to low feedback frequency, $\chi^{2}=2.82$, $\mathrm{p}=0.093$ ), suggesting that a one-sided system will elicit less positive (and probably more accurate feedback) feedback. However, here, the causality appears to be less clear. Unverified buyers might be more likely to be not familiar with the
} 
More evidence comes from Amazon.de, which has a one-sided buyer-to-seller feedback system (Dataset 5, a sample of 320,609 feedbacks). ${ }^{22}$ In addition, we conducted a small email-based survey with a subset of sellers in our sample (see Appendix A.5 for details on data set and survey). Taking the survey responses of 91 Amazon sellers and the field data together, we find that feedback is left by buyers in $41 \%$ of transactions; if we weight the answers by number of transactions, we get a $36 \%$ figure (implying that very active sellers get somewhat less feedback), about half the rate of feedback on the various eBay platforms. ${ }^{23}$ So, overall, the evidence suggests that the scope for reciprocity affects the decision to give feedback.

While the analysis of the field data sets is suggestive of how the proposed solutions may affect reciprocal feedback and feedback giving, they also raise a number of questions. Given the highly complex environments these markets operate in, it is difficult to make clear causal inferences. For instance, the low level of positive feedback in MercadoLivre may stem from uncontrolled crosscountry effects regarding different norms of trading or feedback giving, or from differently developed payment or postal services. Similarly, a comparison of RentACoder.com with eBay is complicated by the fact that the RentACoder.com feedback is on a 10-point scale, the market is smaller, the bidding process and price mechanism are different (coders bid for contracts and buyers do not need to select the lowest price offer), and the networking and trading patterns are likely to differ (e.g., there is likely to be little overlap between program buyers and programmers).

Along the same lines, the field data provide no direct evidence that the reduction in reciprocity improves either the informativeness of feedback or market efficiency. One reason to wonder is that the market in the sample closest to the eBay markets in question, MercadoLivre, exhibits a far higher rate of negative feedback than any other market. ${ }^{24}$ Another reason is the relatively low rates of feedback giving in some of the markets with blind or one-sided feedback: a substantial drop in feedback giving might raise its own credibility issues, effectively substituting one trust problem for

trading and communication norms on the site or to have less long-term interests on the site and so have less incentive to build up a good reputation.

22 Strictly speaking, both sellers and buyers on Amazon are able to submit feedback on each other. However, feedback given to buyers is not accessible to other sellers, while feedback to sellers is published publicly. As a result, sellers typically do not leave feedback. This makes Amazon's system effectively a one-sided one.

${ }^{23}$ We also observe that Amazon feedback is more discriminative than eBay conventional feedback in the sense that only $81.5 \%$ of feedback is given in the best category of 5 , while middle and low feedback of $4,3,2$, and 1 is given in $14.5 \%$, $2.2 \%, 1.0 \%$, and $0.9 \%$ of all cases, respectively.

${ }^{24}$ One response to this concern is that the rate of negative feedback on MercadoLivre accords well with rates of unhappiness uncover by research (ex., Dellarocas and Wood, 2008). However, as the experiment reported in the next section makes clear, we should expect more informative feedback to ignite a number of endogenous effects in the system, starting with buyers better indentifying and shunning untrustworthy sellers, and so the proportion of unsatisfactory trades should be something less than the present rate of unhappiness. 
another. With the exception of RentACoder.com, there is little in the way of before and after data to guide such an analysis.

Finally, the one-sided proposal, which combines eBay's conventional feedback with detailed seller ratings, has no precedent in Internet markets. One of the major arguments for this proposal is that it represents a more modest shift from the existing system than does the blind proposal or truly one-sided systems such as Amazon's. At the same time, it runs its own unique risk in that, under the system, conventional feedback might diverge from the new, more detailed feedback. Again, this might lead to a loss in credibility.

\section{Evidence from a laboratory study}

The questions posed at the end of Section III stem from two problems in evaluating the proposed redesigns on field data alone; problems that we address with an experiment. The first problem is one of comparison. The Internet markets in our data set differ in ways that complicate a direct comparison of feedback systems; in the case of the proposed detailed seller rating system, there is arguably no comparable system in use at all. The experiment is designed as a level playing field for comparing the performance of the different feedback system designs, holding the market environment constant. By the same token, the various experimental controls help us isolating the role of reciprocity for feedback giving and establishing causal relationships between feedback institutions and market behavior. The second problem is one of measurement. The complexity of field Internet markets is such that we have at best indirect measures for feedback informativeness and market efficiency. The experiment provides direct performance measures.

Subsection IV.1 outlines the experimental design. Subsection IV.2 sketches, with a simple model, the performance changes we were expecting to follow from a reduction of feedback reciprocity, and also helps organize the data analysis. Subsection IV.3 shows that the laboratory feedback behavior we observe mirrors key field observations from the conventional system, and that different systems lead to different feedback behaviors. Subsection IV.4 measures the impact of the feedback system on the economic performance of the auction market. Subsection IV.5 shows how market performance is connected to feedback informativeness. 


\section{IV.1 Experimental Design}

The experiment simulates a market with an auction component (including a moral hazard element) that was held fixed across all treatments, and a feedback component that was varied to capture the various scopes for reciprocity across the alternative systems. ${ }^{25}$

Auction component. Each treatment simulates a market that consists of 60 rounds. In each round participants are matched in groups of four, one seller and three potential buyers. Each buyer $i$ receives a private valuation for the good, $v_{i}$, publicly known to be independently drawn from a uniform distribution of integers between 100 and 300 ECU (Experimental Currency Units). Buyers simultaneously submit bids of at least 100 ECU or withdraw from bidding. The bidder with the highest bid (earliest bid in case of a tie) wins the auction and pays a price $p$ equal to the second highest bid plus a 1 ECU increment, or his own bid, whichever is smaller. If there is only one bid, the price is set to the $100 \mathrm{ECU}$ start price. After the auction, all participants in the group are informed of the price and of all bids but the highest. ${ }^{26}$ The price is shown to the seller $s$ who then determines the quality of the good $q_{s} \in\{0, .01, \ldots, .99,1\} .^{27}$ The payoff (not including feedback costs described below) to the seller is $\pi_{s}=p-100 q_{s}$ and to the winning buyer $i$ is $\pi_{i}=q_{s} v_{i}-p$.

Eight sequences of random parameters (valuations, role and group matching), involving 8 participants each, were created in advance. Thus, random group re-matching was restricted to pools of 8 subjects, yielding 8 statistically independent observations per treatment. To ensure a steady growth of experience and feedback, role matching was additionally restricted such that each participant became a seller twice every 8 rounds. The same 8 random game sequences were used in all treatments. Participants were not informed about the matching restriction. There were 32 participants in a session and 2 sessions per treatment.

Feedback component. When the auction ends in a trade, both buyer and seller have the opportunity to give voluntary feedback on the transaction partner. Giving feedback costs the giver 1 ECU, reflecting the small effort costs when submitting feedback.

In the Baseline treatment, both the seller and the buyer can submit conventional feedback (CF), rating the transaction negative, neutral, or positive. Feedback giving ends with a "soft close": In a

\footnotetext{
25 See Appendix B.1 for a translation of experimental instructions.

${ }^{26}$ For simplicity, we chose a sealed-bid format and abstracted away from eBay's bidding dynamics, which is known to create incentives for strategic timing in bidding (Roth and Ockenfels, 2002). Other features such as the handling of increments and the information feedback are chosen analogously to eBay's rules.

${ }^{27}$ In the experiment, sellers were asked to choose an integer between $0 \%$ and $100 \%$. Proportions simplify the notation.
} 
first stage, both transaction partners have the opportunity to give feedback. If both or neither give feedback, then both are informed about the outcome and the feedback stage ends. If only one gives feedback, the other is informed about that feedback and enters the second feedback stage where he has again the option to give feedback, and so a chance to react to the other's feedback. ${ }^{28}$ As on eBay, a trader's conventional feedback is aggregated over both buyer and seller roles as the feedback score and the percentage of positive feedbacks (Section II). When the participant becomes a seller, these scores are presented to potential buyers on the auction screen prior to bidding.

The Blind treatment differs from the Baseline only in that we omit the second feedback stage. That is, buyer and seller give feedback simultaneously, not knowing the other's choice.

The DSR (Detailed Seller Rating) treatment adds a rating to the Baseline treatment feedback system. After giving CF, the buyer (and only the buyer) is asked to rate the statement "The quality was satisfactory" on a 5-point Likert scale: "I don't agree at all”, “I don’t agree”, "I am undecided", "I agree", "I agree completely". As in the Baseline treatment, we implement a soft close design, but in case the seller delays and enters the second feedback stage, she is only informed about the conventional feedback given by the buyer, not about the detailed quality rating. Number and average of received detailed seller ratings are displayed at the auction page.

All sessions took place in April 2007 in the Cologne Laboratory for Economic Research. Participants were recruited using an Online Recruitment System (Greiner, 2004). Overall 192 students participated in 6 sessions. After reading instructions and asking questions, participants took part in two practice rounds (see Appendix B). Each participant received a starting balance of 1,000 ECU to cover potential losses. Sessions lasted between $1 \frac{1}{2}$ and 2 hours. At the end of the experiment, the ECU balance was converted to Euros at a rate of $200 \mathrm{ECU}=1$ Euro, and was paid out in cash. Participants earned 17.55 Euros on average (standard deviation $=2.84$ ), including a show-up fee of 2.50 Euros and 4 Euros bonus for filling in a post-experiment questionnaire.

The experiment is designed to isolate the reciprocal relationship between traders. In particular, the experiment abstracts away from any buyer moral hazard: each winning bid is automatically transferred to the seller. Thus, the feedback given by sellers to buyers is not informative, because it cannot represent reputational information on the trader's behavior as a seller. ${ }^{29}$ Yet, as on eBay,

\footnotetext{
${ }^{28}$ Klein et.al. (2007), as well as our data, support this characterization of the conventional eBay system. Ariely, Ockenfels, and Roth (2005) and Ockenfels and Roth (2006) model the ending rule of Amazon.com auctions in a similar way, allowing buyers to always respond to other bids.

${ }^{29}$ Insofar buying behavior is uncorrelated with selling behavior, this also holds for eBay.
} 
leaving feedback on a buyer may affect the buyer's future profits as a seller, because a trader's reputation depends on feedback earned both as a buyer and a seller. So positive feedback may be effectively rewarded and negative feedback may be retaliated.

\section{VI.2 A characterization of how reciprocal feedback may affect market outcomes}

Towards clarifying our hypotheses, we sketch a simple model that characterizes how a less reciprocal feedback system might improve market efficiency in the experiment. A full-fledged theory of reputation production and reputation building being beyond the scope of the present study, we assume away several complexities and do not explicitly model the underlying motivational mechanisms for reciprocity. We concentrate instead on what we believe captures the essence of the effect of distorted feedback on economic efficiency both in the lab and on eBay.

The experiment has a finite number of trading rounds. Assuming that all agents are commonly known to be selfish and rational, the unique subgame-perfect equilibrium in all treatments of the experiment stipulates zero feedback giving and quality tendered, with no auction bids. The socially efficient outcome has the bidder with the highest valuation winning the auction, the seller producing $100 \%$ quality, with no (costly) feedback giving. So both of these, rather extreme, scenarios leave no role for the feedback system. If, as seems more likely, feedback is used to build up reputation and to discriminate between sellers, we hypothesize that reciprocal feedback hampers market efficiency because reciprocity compresses reputation scores in a way that makes it harder for buyers to discriminate between sellers; these sellers then have less incentive to deliver good quality. Consequently, the two proposed redesigns, if they diminish the role of reciprocity, should do better.

To fix ideas (and extending the notation established in Section VI.1), suppose that a seller's reputation is given by a feedback score $r_{s}$, which we normalize to be between [0,1]. In our laboratory private-value auction context, a rational, risk-neutral bidder $i$ then bids $b_{i}=q^{e}\left(r_{s}\right) v_{i}$, where $q^{e}\left(r_{s}\right)$ is the expected quality given the seller's feedback score $r_{s}$.

For simplicity, we assume that, after all sales, the seller chooses the same quality (so we ignore endgame effects). Then the question for the seller is to set the optimal (stationary) shipping policy, $q_{s}$. Define 'perfectly discriminative' scoring as a strictly monotonic relationship between $r_{s}$ and $q_{s}$, so that a score reveals a seller's shipping policy; e.g., $q^{e}\left(r_{s}\left(q_{s}\right)\right)=q_{s}$. Under perfectly discriminative scoring with $n$ bidders, with normalized private values $\left[0, v_{H}\right]$, and $\operatorname{cost} c q_{s}$ to ship quality $q_{s}$, a profitmaximizing seller chooses $q_{s}$ to maximize

$$
((n-1) /(n+1)) q^{e}\left(r_{s}\left(q_{s}\right)\right) v_{H}-c q_{s}=((n-1) /(n+1)) q_{s} v_{H}-c q_{s} .
$$


Inspection shows that, for $c$ not too high, a seller's optimal choice is full quality, $q_{s}=1$. That is, a feedback system that generates perfectly discriminative scores can effectively cope with moral hazard and adverse selection problems. ${ }^{30}$

Reciprocal feedback in our context implies that the reputation score tends to be biased upwards. The simplest way to capture this distortion, is to write the relationship between $r_{s}$ and $q_{s}$ as

$$
r_{s}\left(q_{s}\right)=a+((1-a) /(1-b)) q_{s} \text { for } q_{s}<1-b \text { and some } a, b \in(0,1), \text { and } 1 \text { otherwise. }
$$

Both $a$ and $b$ measure the distortion of the reputation score that comes with reciprocity compared to a perfect score that directly reflects quality $(a=b=0)$. More specifically, the parameter $b$ describes the length of the interval of qualities that now all yield the maximum reputation score $\left(r_{s}=1\right)$, the idea being that buyers are not willing to take the risk of retaliatory feedback if the quality reduction is sufficiently small. ${ }^{31}$ The parameter $a$ measures the 'compression' of the overall range of feedback due to reciprocity. In our simple model, however, only the distortion that comes with $b$ affects the economic performance of the market (see below), while $a$ downscales scores without affecting the monotonic relationship between $r_{s}$ and $q_{s}$

Returning to the seller's choice optimization problem, inspection shows that with reciprocal feedback, the optimal choice(s) for those who choose a quality level below $1-b$ remain(s) unchanged compared to a system yielding perfectly discriminative scores. However, all qualities above $1-b$ are 'squeezed' at $q_{s}=1-b$. Consequently, the bigger the distortion $b$ induced by reciprocity, the lower quality shipped, the lower bids, the lower prices, and the lower market efficiency. As we will see, the lab data are to a large extent consistent with the model's basic predictions and mechanisms. ${ }^{32}$

\section{IV.3 Feedback Behavior}

In this section, we investigate whether the feedback pattern in the Baseline treatment mirrors the pattern observable in the field, and how the feedback behavior in the alternative systems compares.

\footnotetext{
30 Moral hazard is important when choosing the quality level. Adverse selection problems may arise because of heterogeneity in traders' costs or (social) preferences (not being explicitly modeled here).

31 The fact that a large majority of eBay traders accumulated only positives (Section II) seems to support the hypothesis that there is too little discrimination among those with maximum scores.

32 In our model, a reputation score gained in a system with reciprocal feedback is less informative in the sense that it does not discriminate between qualities above a certain threshold. However, in equilibrium, even with reciprocity, there is no uncertainty about a seller's quality level given the reputation score. A more realistic model could add noise to the feedback, such that more compressed feedback makes it harder to correctly predict quality from the reputation score. Alternatively, one could allow some sellers to be intrinsically motivated to deliver good quality, regardless of the distortions in reputation scores. Such model extensions may capture the idea that reciprocity in feedback giving induces (more) uncertainty about a seller's quality.
} 
Feedback giving. In the Baseline treatment, buyers give feedback in about $80 \%$ and sellers in about $60 \%$ of the cases, with an average of about 70\%, very similar to what is observed in the field (Section II). Relative to Baseline, Blind exhibits significant drops in both buyer (68\%) and seller (34\%) giving frequencies (two-tailed Wilcoxon $p<0.025$ in both cases), whereas DSR exhibits only minor and insignificant reductions for both buyers $(77 \%)$ and sellers $\left(57 \% ; p>0.640\right.$ in both cases). ${ }^{33}$

Feedback timing. When possible, sellers tend to wait until buyers have given feedback (Table 3; Wilcoxon two-tailed $p<0.025$ both in Baseline and DSR). This effect is most pronounced when feedback is mutually neutral/negative; the only case with buyers more often moving second is - like in the field data - when the buyer gives a problematic and the seller a positive conventional feedback (see Table 11 in Appendix $C$ for details).

TABLE 3: TIMING OF FEEDBACK

\begin{tabular}{|c|c|c|c|}
\hline & Baseline & Blind & DSR \\
\hline Both first round & $27 \%$ & $26 \%$ & $29 \%$ \\
\hline None first round & $16 \%$ & $24 \%$ & $15 \%$ \\
\hline Seller $1^{\text {st }}$, buyer in $2^{\text {nd }}$ & $4 \%$ & & $2 \%$ \\
\hline Seller $1^{\text {st }}$, Buyer not (in $2^{\text {nd }}$ ) & $5 \%$ & $8 \%$ & $8 \%$ \\
\hline Buyer $1^{\text {st }}$, seller in $2^{\text {nd }}$ & $24 \%$ & & $17 \%$ \\
\hline Buyer $1^{\text {st }}$, Seller not (in $\left.2^{\text {nd }}\right)$ & $23 \%$ & $42 \%$ & $28 \%$ \\
\hline
\end{tabular}

Feedback content. Table 4 shows correlations between conventional feedbacks across treatments. We find that blindness of feedback significantly decreases the correlation compared to the open systems. The high correlations in the latter are mainly driven by the cases where sellers delay their feedback and give second, while when both transaction partners give feedback in the first stage, correlations are comparable to blind feedback. However, correlations of simultaneously submitted feedback are significantly different from zero, too.

\footnotetext{
33 Regression analysis considering interaction effects of treatments with quality support the finding (Table 10 in Appendix C) and furthermore show that buyers give significantly more often feedback when quality is low in both alternative designs. We discuss feedback giving correlations below.
} 
TABLE 4: KENDALL TAU CORRELATIONS

BETWEEN SELLER AND BUYER FEEDBACK BY TIMING

\begin{tabular}{lcccc}
\hline \hline & Both 1 & S 1st, $\mathrm{B} 2^{\text {nd }}$ & B 1 st $^{\text {S S 2 }}{ }^{\text {nd }}$ & All \\
\hline Baseline & 0.359 & 0.536 & 0.901 & 0.680 \\
Blind & & & & 0.411 \\
DSR & 0.533 & $0.730^{+}$ & 0.913 & 0.759 \\
\hline \hline
\end{tabular}

Note: All correlations highly significant at the $0.1 \%$ level, except for cell indicated by ${ }^{\dagger}$ which is weakly significant at the $10 \%$ level.

Negative feedback. Finally, the probit regression in Table 5 shows the determinants of problematic feedback given to sellers conditional on the buyer giving feedback (where problematic feedback is defined as either a negative or neutral conventional feedback or a detailed seller rating of 3 or less). Controlling for quality, price and other factors, we see that problematic feedback increases in both Blind and DSR. The coefficient estimates for the two treatment dummies are nearly identical, indicating that the size of the effect is about the same in both treatments. ${ }^{34}$

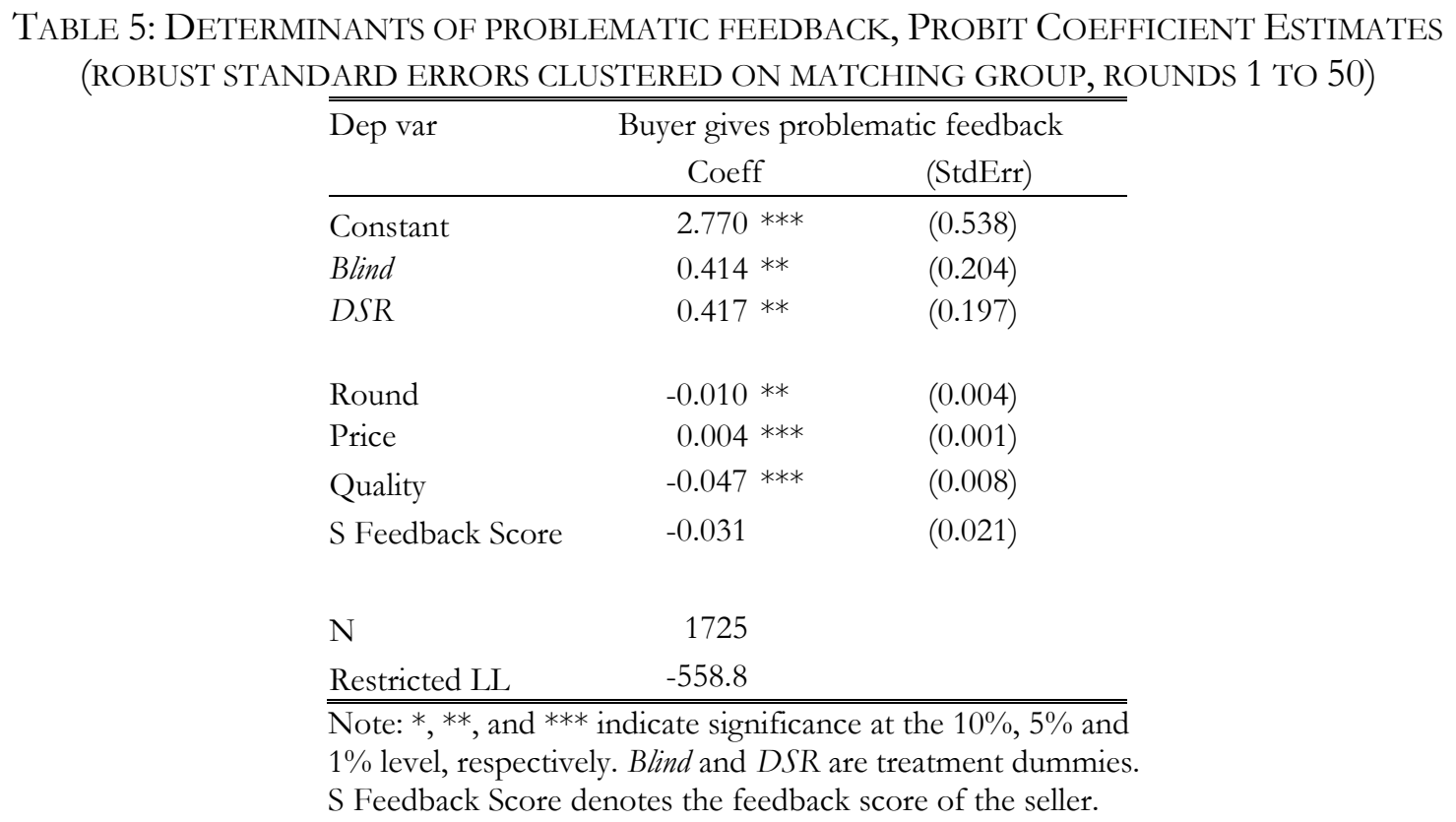

The reason for more negative feedback is that buyers receiving poor quality are more likely to give problematic feedback under the alternative systems. More specifically, Figure 3 illustrates that in all treatments, a positive conventional feedback (and the highest DSR) is awarded for quality of $100 \%$; likewise, very low quality receives negative feedback in all cases. The major difference between the treatments happens between $40 \%$ and $99 \%$ quality; here average conventional feedback

34 The same probit, run on all successful auction data (so not conditional on the buyer giving feedback) yields similar results save the coefficient for the Blind treatment is somewhat smaller (still positive) but insignificant, most likely because of the drop in feedback frequency we observed earlier for that treatment. 
given is tougher in Blind and DSR. In this range, conventional feedback given in DSR is not quite as tough, but observe that the DSRs given generally line up well the Blind conventional feedback; that is, the DSRs reflect similar, tougher buyer standards as those revealed in Blind.

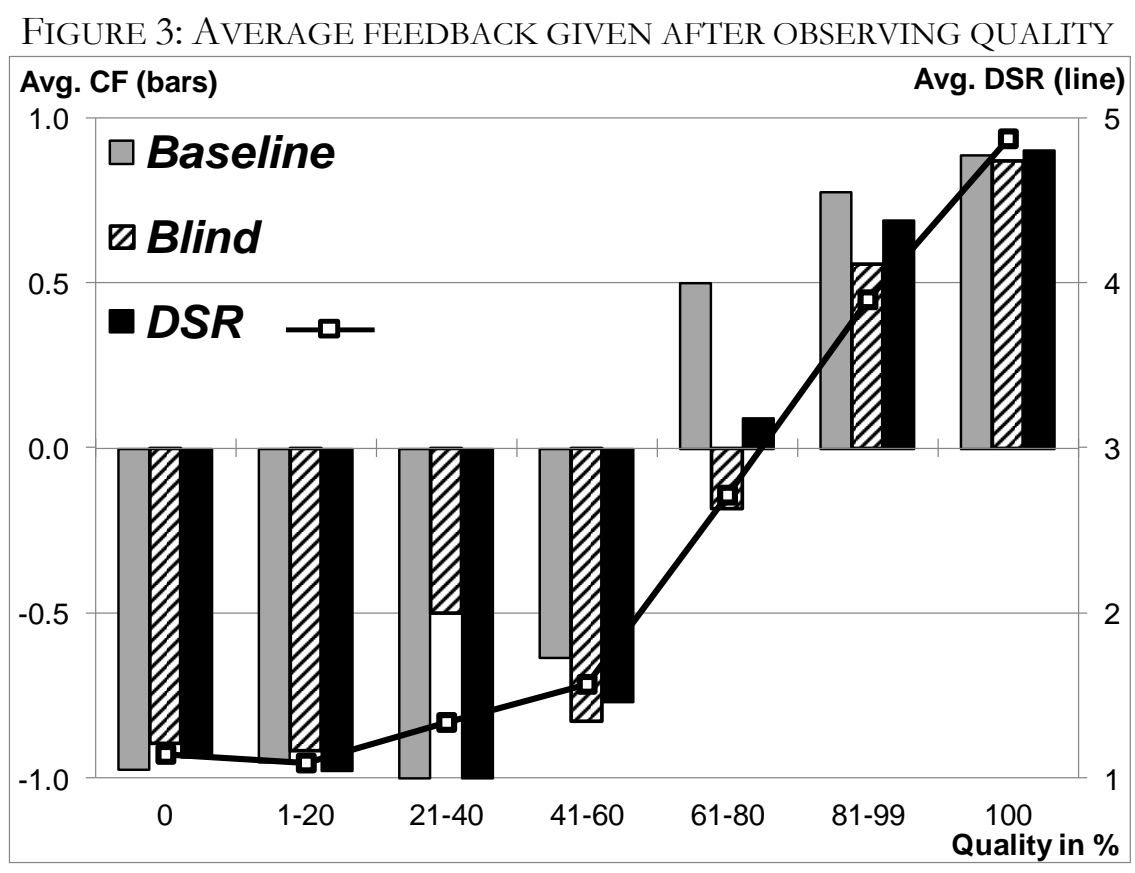

Summing up, the Baseline treatment replicates in considerable detail the qualitative pattern of strategic timing, retaliation and correlation of feedback found on eBay. ${ }^{35}$ Moreover, as predicted, the alternative systems successfully mitigate reciprocity (as shown, for instance, by reduced correlations of feedback content) and so allow for a more negative response to lower quality.

\section{IV.4 Quality, Prices, and Efficiency}

The hypothesis underlying our redesign efforts is that the extent to which feedback is shaped by reciprocity affects economic outcomes. More specifically, following the model sketched in Section IV.2, we hypothesize that diminishing the role of reciprocity increases quality, prices and efficiency. Figure 4 shows the evolution of quality and auction prices over time: both quality and prices are higher in both DSR and Blind than in Baseline. Applying a one-tailed Wilcoxon test using independent

\footnotetext{
35 There are only two major exceptions. First, there is no endgame effect in the field, because there is no endgame. Second, we have much more negative feedback in all our treatments compared to eBay. This is wanted, because given the rareness of negatives on eBay it would otherwise be difficult to study reciprocal feedback giving and especially feedback retaliation.
} 
FIgURE 4: AVERAGE AUCTION PRICES AND SELLERS’ QUALITY CHOICES OVER TIME
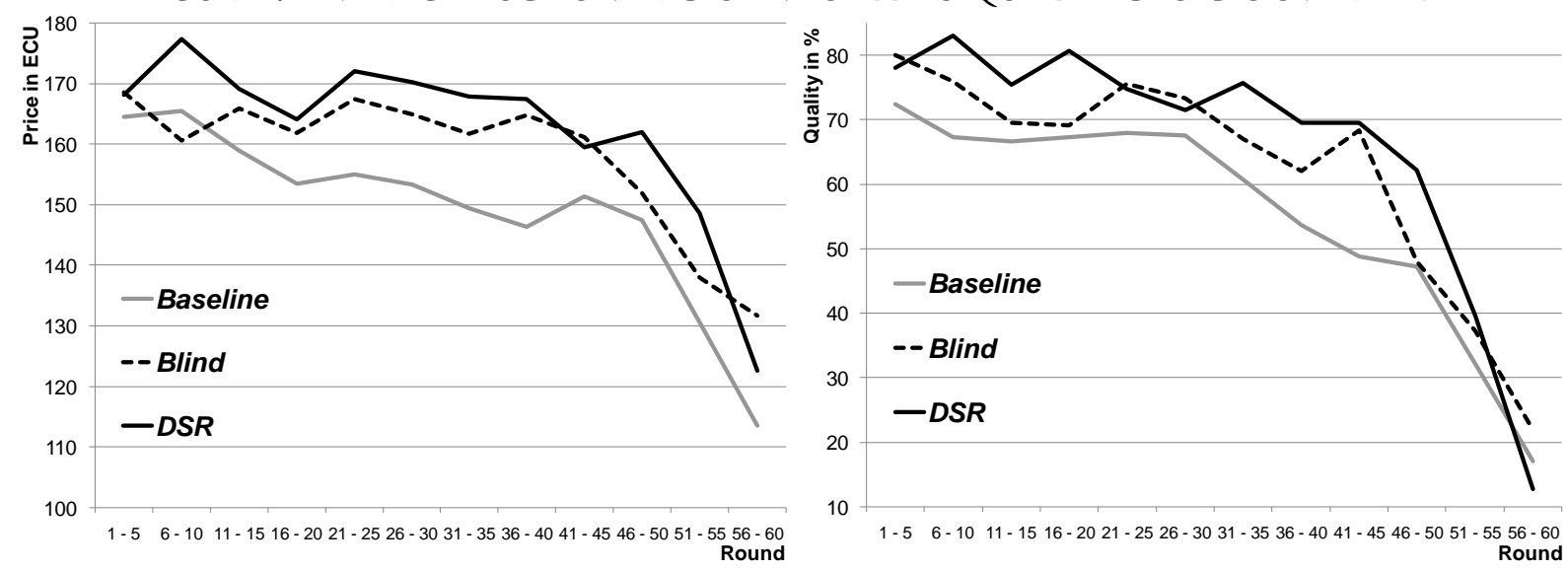

TAble 6: Determinants of Quality and PRice, Tobit CoefFicient Estimates (ROBUST STANDARD ERRORS CLUSTERED ON MATCHING GROUP, ROUNDS 1 TO 50)

\begin{tabular}{|c|c|c|c|c|c|c|c|c|}
\hline \multirow{3}{*}{$\begin{array}{l}\text { Dep var } \\
\text { Model }\end{array}$} & \multicolumn{4}{|c|}{ Quality } & \multicolumn{4}{|c|}{ Price } \\
\hline & \multicolumn{2}{|l|}{1} & \multicolumn{2}{|c|}{2} & \multicolumn{2}{|c|}{1} & \multicolumn{2}{|l|}{2} \\
\hline & Coeff & (StdErr) & Coeff & (StdErr) & Coeff & (StdErr) & Coeff & (StdErr) \\
\hline Constant & $36.59 * * *$ & (9.659) & $45.75 * * *$ & (9.053) & $158.85 * * *$ & (5.923) & $166.93 * * *$ & (4.795) \\
\hline Blind & $20.75 * * *$ & $(7.813)$ & & & $20.22 * *$ & (8.685) & & \\
\hline DSR & $21.27 * * *$ & (5.105) & & & $12.57 * *$ & (6.321) & & \\
\hline Round & $-1.17 * * *$ & $(0.186)$ & $-1.13 * * *$ & $(0.210)$ & $-1.24 * * *$ & $(0.144)$ & $-1.18 * * *$ & $(0.157)$ \\
\hline S FScore & & & $3.85 * * *$ & $(0.977)$ & & & $5.63 * * *$ & $(0.944)$ \\
\hline S FScore*Blind & & & $3.38^{* *}$ & $(1.696)$ & & & 3.41 *** & $(0.807)$ \\
\hline S FScore* $D S R$ & & & 1.05 & $(1.200)$ & & & -0.604 & (1.013) \\
\hline S DSR Avg & & & $6.22 * * *$ & $(1.970)$ & & & $3.75 * *$ & $(1.847)$ \\
\hline Price & $0.216 * * *$ & $(0.045)$ & $0.222 * * *$ & $(0.045)$ & & & & \\
\hline $\mathrm{N}$ & 228 & & 228 & & 228 & & 2283 & \\
\hline Restricted LL & -7944 & & -793 & & -1103 & & -11038 & \\
\hline
\end{tabular}

Note: *,**, and *** indicate significance at the $10 \%, 5 \%$ and $1 \%$ level, respectively. Blind and DSR are treatment dummies. S FScore denotes the (conventional) feedback score of the seller, and S DSR Avg the seller's average DSR score.

matching group averages, the increases in average quality and price over all rounds are significant for treatment DSR ( $p=0.035$ and 0.025, respectively), but not for Blind. The test, however, aggregates over all rounds, and there is a sharp end game effect in all treatments, with both quality and prices falling towards zero, consistent with related studies on reputation building in markets. ${ }^{36}$ Regressions controlling for round and end game effects yield strong and significant positive treatment effects

${ }^{36}$ See for example Selten and Stöcker (1986) and Bolton et al. (2005). 
regarding bids and quality for both DSR and Blind, with similar magnitude (see Price Model 1 and Quality Model 1 in Table 6).

The choice of bid and quality levels affects efficiency. In the Baseline treatment, $47 \%$ of the potential value was realized, with losses of $23 \%$ and $31 \%$ resulting from misallocation and low quality, respectively. ${ }^{37}$ Both alternative systems increase efficiency, yet only DSR does significantly so; there is a $27 \%$ increase in efficiency in DSR $(p=0.027)$ compared to Baseline, and a $16 \%$ increase in Blind $(p=0.320) .{ }^{38}$ Both market sides gain (although not significantly so) in the new system: about $45 \%(56 \%)$ of the efficiency gains end up in the sellers' pockets in DSR (Blind), and the rest goes to buyers. So both alternative systems increase price, quality and efficiency. DSR improvements are economically and statistically significant, while efficiency improvement in Blind is not significant.

\section{IV.5 The relationship between feedback informativeness and improvement in market performance}

We have seen in Subsection IV.3 that the alternative systems lead to less reciprocal feedback, and in Subsection IV.4 that they lead to improved market outcomes. But how does less reciprocity actually translate into better market performance? The natural hypothesis is that, for a given quality, less reciprocity in feedback giving generates reputation scores that allow better forecasting of sellers' future behavior (see the model in Subsection IV.2). That this is so is evident from Quality Model 2 in Table 6. The model shows that seller conventional feedback scores in Blind have significantly higher positive correlation with the quality the seller provides at that point then is the case in Baseline. The positive correlation between quality and conventional feedback scores increases in DSR as well, but not significantly so. Observe, however, that the DSRs are significantly positively correlated with quality and so, in this sense, the DSR seller scores, as well as those in Blind, exhibit less distortion than those in Baseline.

We expect that introducing one of the alternative systems leads sellers to react to better feedback informativeness by shipping higher quality in Blind and DSR compared to Baseline (see the model in Subsection IV.2). Returning again to Table 6, the Price Model 2 shows that nominally equivalent

\footnotetext{
37 A misallocation occurs if the bidder with the highest valuation does not win so that welfare is reduced by the difference between the highest valuation and the winner's valuation (which we define as the seller's opportunity cost of 100 when there is no winner because of lack of bids). Low quality leads to an efficiency loss because each percent quality the seller does not deliver reduces welfare gains by one percent of the auction winner's valuation, minus one. Also, each feedback reduces welfare by 1 ECU, but this source of efficiency loss is negligible as in no treatment feedback costs exceed $1 \%$ of maximal efficiency.

38 Reported $p$-values are from a one-tailed Wilcoxon matched pairs signed ranks test on fully independent group averages.
} 
conventional feedback scores in Baseline and Blind lead to higher prices in the latter case. In comparing Baseline and DSR, there is little difference in regard to conventional feedback impact on price; however, DSRs are significantly positively correlated with price, and in this sense sellers with good feedback scores are more highly rewarded in DSR than in Baseline.

More evidence comes from looking directly at the effect a quality decision has on a seller's future average profit. Model 1 in Table 7 shows that the amount of quality a Baseline seller chooses in the present round drives up future average profit, but not significantly so. In contrast, the amount of quality a Blind or DSR seller chooses drives up their future expected profit by a higher and significant amount, and by about the same amount for both treatments. ${ }^{39}$

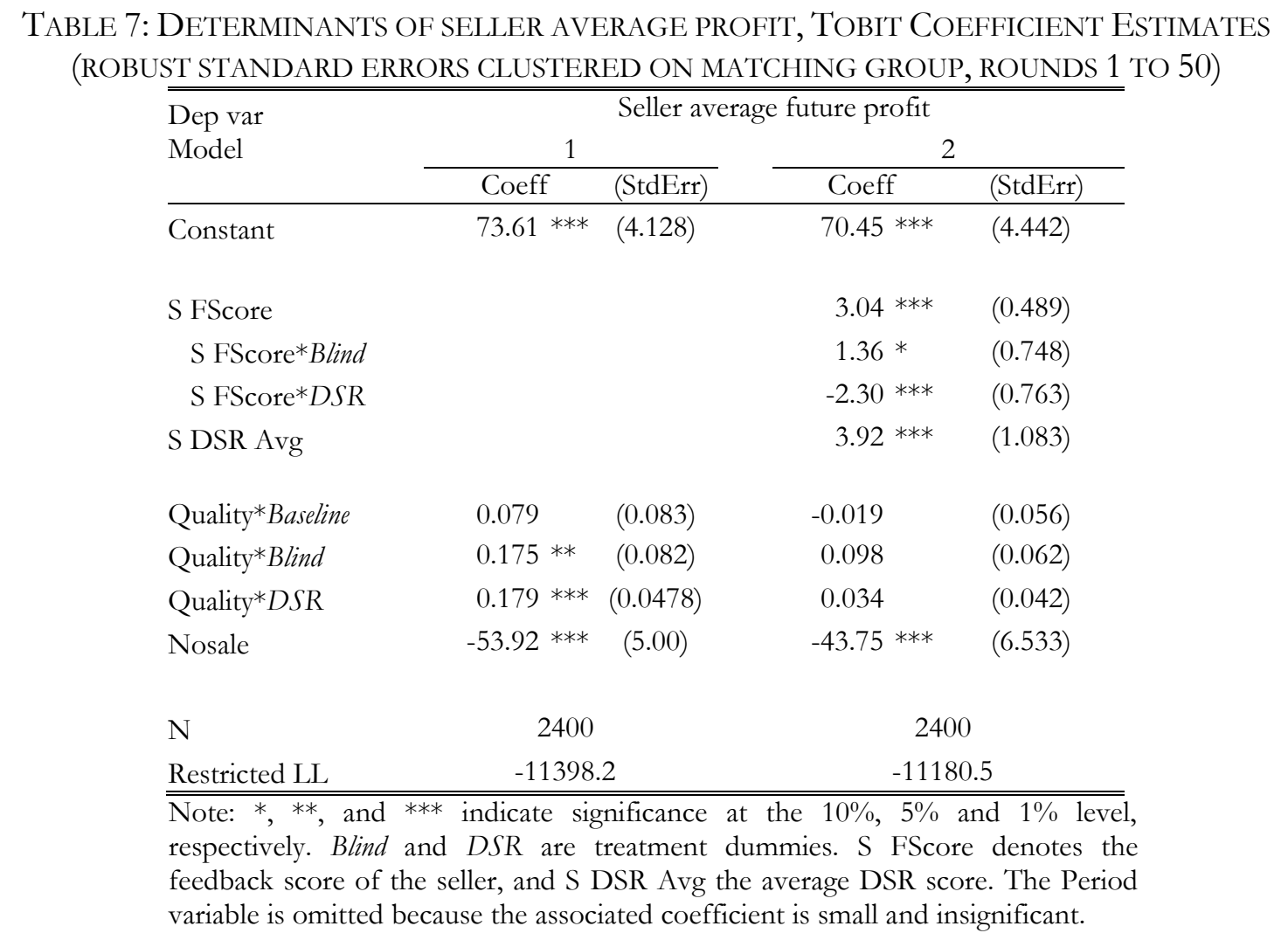

To conclude, the experiment mirrors the feedback pattern on eBay pretty well. This gives us confidence that the experiment captures relevant aspects of the field behavior - even though it abstracts away from buyer moral hazard and other features such as mutual feedback withdrawal that

\footnotetext{
39 As a side note, observe that Model 2 in Table 7 shows that knowing a seller's feedback score has greater value for forecasting a seller's future average profit than does knowing the quality decision they make in the present round, in all three treatments. That is, a summary statistic of a seller's feedback history is a better predictor of his future profitability than observing directly what he did in the present.
} 
may confound the analysis of feedback giving in the field. Data from other market platforms such as RentACoder.com and MercadoLivre suggest that, in particular, blindness might reduce feedback correlation and feedback giving. The experiment replicates these findings in a highly controlled environment, showing that the change of institutions is in fact causal to the observations - although other factors like cross-cultural behavior differences may add to the field patterns. Taken together, the lab and field evidence thus provide a coherent picture of the role of reciprocity in feedback systems. In addition, the experiment complements the field data both by measuring variables that are unobservable in the field and by test-bedding designs that are nonexistent in the field. More specifically, the experiment shows that both systems significantly increase the informativeness of the feedback system, and how the effect is attributable to changes in feedback, bids relative to valuation, and product quality, most of which are difficult to observe in the field. Regarding design, DSR yields significant efficiency gains over the baseline treatment and does not experience a significant drop in the number of feedbacks. Because this is not the case for Blind, at least not significantly so, the experiment suggests that DSR would be the better option for a system change.

\section{A first look at the field implementation of detailed seller ratings}

The theoretical, laboratory and field analyses described above suggest that the DSR system outperforms the traditional system and does no worse - and along some dimensions better - than a blind system. Because of this and because of the path dependency concerns mentioned in Section II.3, eBay decided to go for a detailed seller rating feedback system under the name "Feedback 2.0" in spring $2007 .^{40}$ Under Feedback 2.0, in addition to the conventional feedback, buyers can leave ratings in four dimensions on a 5 point scale. These dimensions are "How accurate was the item description?", "How satisfied were you with the seller's communication?", "How quickly did the seller ship the item?", and "How reasonable were the shipping and handling charges?" For each of these ratings, only the number of feedbacks and the average rating are displayed on the seller's feedback page, and only after the seller receives at least 10 ratings. ${ }^{41}$ On the feedback submission page eBay emphasizes that only averages and no individual DSRs can be observed. As a result, DSR is not only blind (in the sense that it cannot be responded to) and one-sided (only buyers can give

\footnotetext{
40 EBay piloted the new design in a couple of smaller and medium size eBay markets from early March 2007 (Australia, Belgium, France, India, Ireland, Italy, Poland, and UK), and introduced it worldwide in the first week of May 2007.

${ }^{41}$ See Figures 9 and 10 in Appendix C for screen shots. Similar to conventional feedback, DSRs are averaged for each buyer before being aggregated. Also, DSRs older than 12 months are ignored, yielding a 'rolling' average. There are a number of other small changes implemented jointly with Feedback 2.0. For instance, information about item title and price were added to feedback comments received as a seller.
} 
detailed ratings), but also anonymous (sellers cannot identify the DSR provider). In this section we present early evidence on the performance of the new system.

FIGURE 5: EVOLUTION OF POSITIVE, NEUTRAL, NEGATIVE AND WITHDRAWN FEEDBACK BEFORE AND AFTER INTRODUCTION OF FEEDBACK 2.0

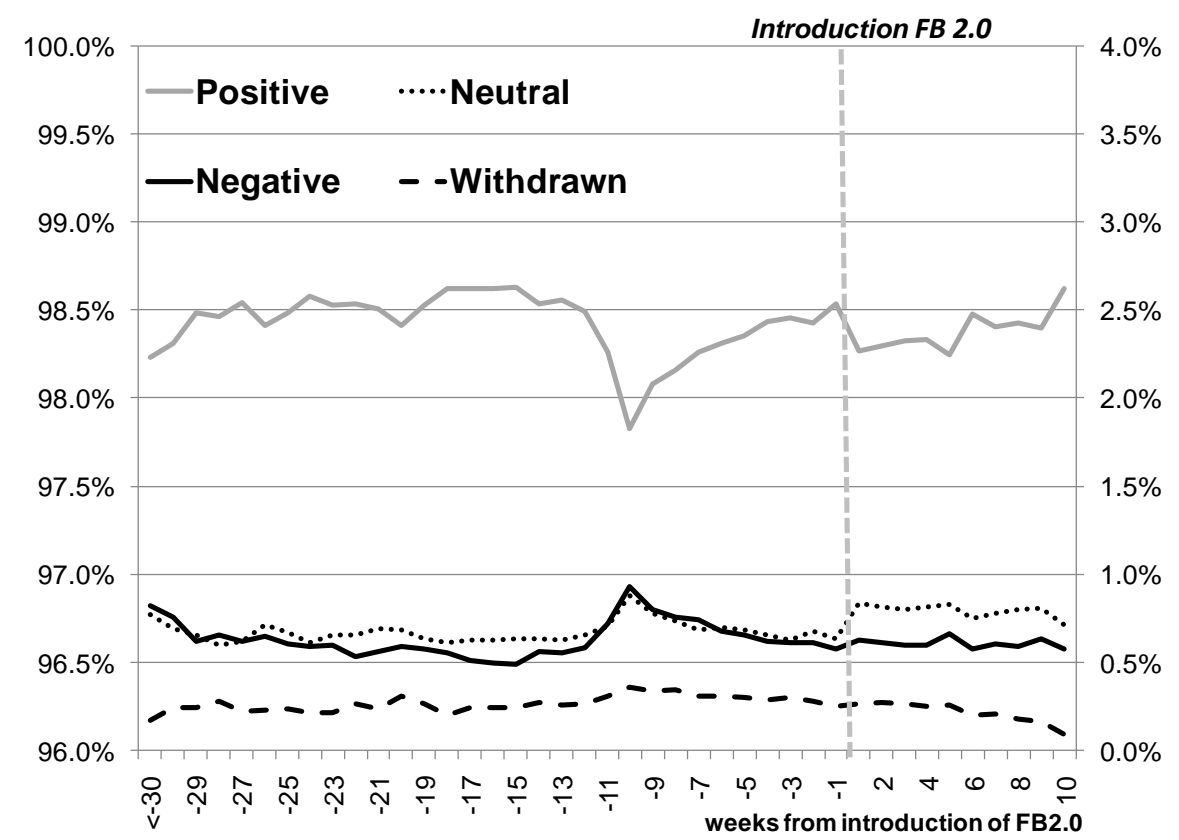

Notes: The figure is based on about 7 and 3 million individual feedbacks in the 30 weeks before and the first 10 weeks after introduction of Feedback 2.0, respectively, in the pilot countries Australia, Belgium, France, Poland and UK. Positive feedback is plotted on the left y-axis, all other feedback on the right y-axis.

The first observation is that conventional feedback giving is not much affected by the system change. Based on Dataset 1 (see Appendix A.1), Figure 5 shows the share of positive (left y-axis) as well as neutral, negative and eventually withdrawn feedback (right y-axis) for the last 30 weeks before and the first 10 weeks after introduction of DSR in early March 2007 (vertical dashed line). The shares are quite stable, with the exception of the kink about 10 weeks before the system change, which falls in the pre-Holiday shopping time known for high expectations and time pressure. From the week before to the week after DSR introduction we observe a small drop in positive and an accompanying rise in neutral feedback. This is in line with the experimental results on the DSR system, where we also observe a shift from positive to neutral feedback. However, these changes are small compared to the Holiday shock and overall variance, and seem not to be persistent, at least for positive feedback. We also do not observe significant changes in CF (conventional feedback) 
frequency, timing or correlation between the pre- and post change Datasets 1 and 2. We conclude that, overall, there are no or at best small short-term effects in CF due to the introduction of DSR.

DSRs are given in about $70 \%$ of the cases CF is given, varying somewhat by country and category. For the 27,759 eBay members from Australia, Belgium, France, Poland and UK in Dataset 1, who received at least ten DSRs between the first week of March and data collection in May 2007 (such that their DSR average was published on their feedback profile), we track CF received as a seller in the same period as well as in the two months before DSR introduction (using individual feedback data; see Appendix A.1 for a description). From this feedback we calculated the fictitious percentage positives of CF of each individual seller before and after introduction of Feedback 2.0, using only those feedbacks given in the corresponding time windows.

Figure 6: Distribution OF AVERAGE CF AND DSR SCORES IN MEMBER PROFILES

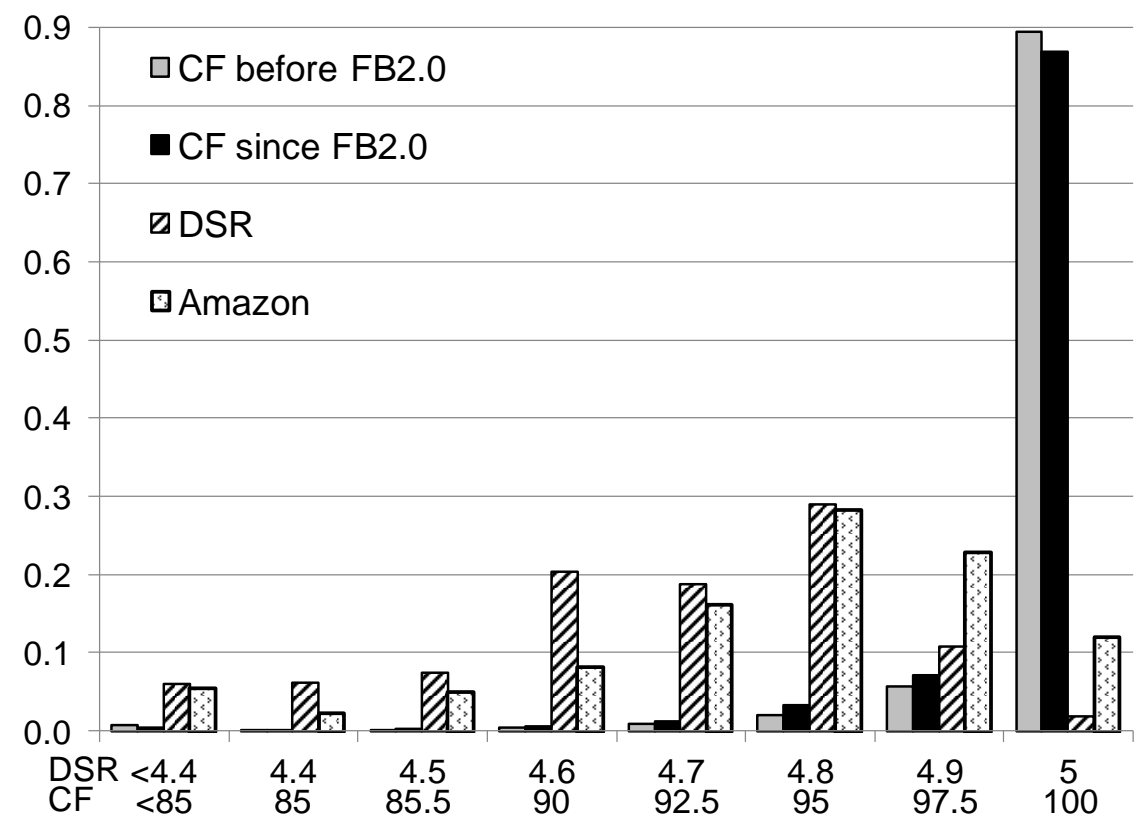

Notes: DSR and Amazon.com's 1-5 range and CF percent positive's 0-100 range are divided in the same number of categories and are aligned at the $\mathrm{x}$-axis. EBay data is based on the feedback of the same 27,759 members from Australia, Belgium, France, Poland and UK, received as seller in Jan/Feb 2007 and March/Apr/May 2007, respectively. Inclusion criterion was more than 10 DSRs in at least one DSR category. Amazon data is based on 9,741 Amazon market place sellers.

In line with Figure 5 above, Figure 6 shows that the CF percentage positives scores slightly decreased after introduction of the new system. However, DSRs are more nuanced. For instance, while most sellers have a 'perfect' CF reputation of $100 \%$, only very few have a 'perfect' average DSR of 5. For comparison we also include the distribution of average scores of Amazon.com 
marketplace sellers in Figure 6 (based on Dataset 5, see Appendix A.5). The one-sided DSR feedback distribution follows the one-sided Amazon.com feedback distribution fairly closely, although it seems to be even somewhat more negative. This supports the idea that DSR is treated as a one-sided system, with little scope for reciprocity. In fact, Figure 7 shows that the difference in rating variability between CF and DSR is partly driven by a strategic response to the differences in the scope for reciprocal behavior.

\section{FIGURE 7: DISTRIBUTION OF CF CONDITIONAL ON AVERAGE OF CORRESPONDING DSRS}

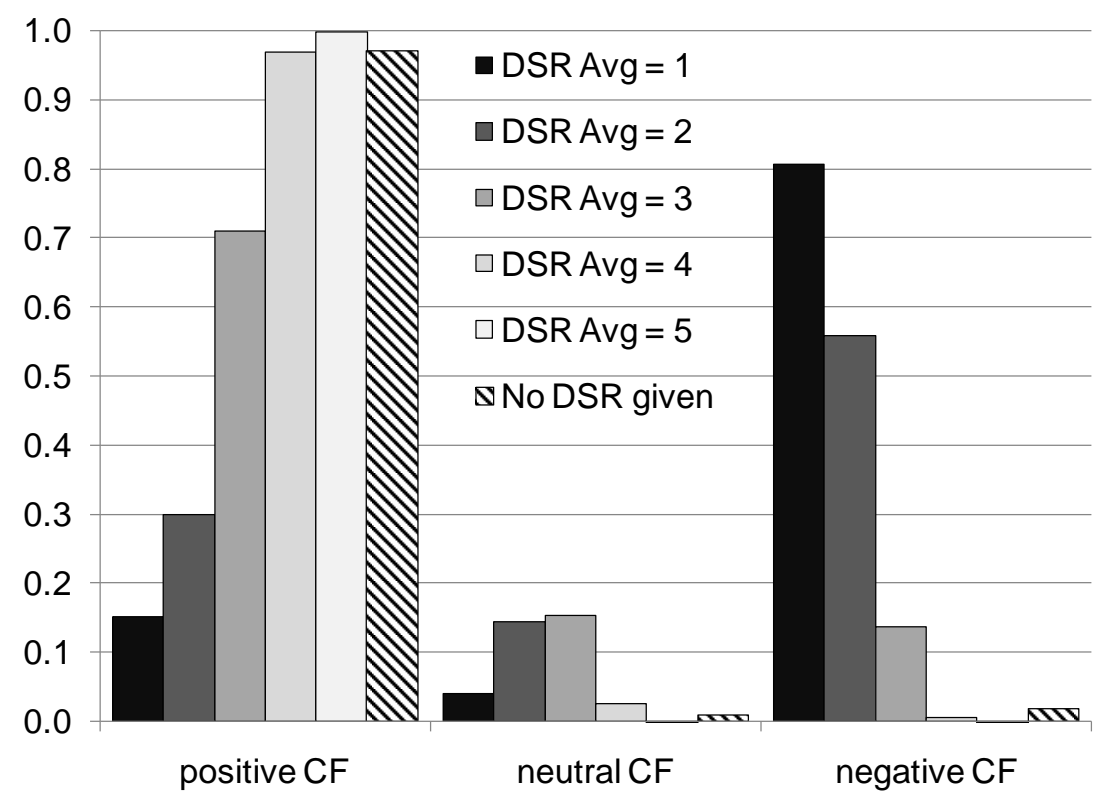

Notes: To calculate the DSR average we take all available of the up to four DSR ratings per feedback, average and round to integer. Thus, a DSR average of 1 implies two or three ratings of 1 and at most one rating of 2 .

Figure 7 (based on Dataset 2; see Appendix A.2 for a description) shows for each DSR average the distribution of the corresponding CFs. As one might expect, when the DSR average is 5, virtually all CF is positive, and when the DSR average is 4, almost all CF is positive. However, of those buyers who submit the minimum DSR average of 1 (that means that the buyer gave one of the rating combinations $1,11,111,112,1111$, or 1112 ), about $15 \%$ submit a positive CF. For DSR averages of 2 , this share is $30 \%$. That is, among those who are maximally unsatisfied measured by DSR, which cannot be reciprocated, a substantial share expresses satisfaction with respect to CF, which can be reciprocated. It seems plausible that at least part of this pattern can be interpreted as hiding bad detailed seller ratings behind a positive conventional feedback. 
The initial concern that this kind of strategic hiding behavior might yield inconsistencies between aggregate CFs and DSRs is not borne out, however. The overall share of DSR averages of 1 or 2 is only slightly less than $2 \%$, so that on average, a positive CF comes with a better DSR.

Strategic feedback hiding is only effective when the seller is not able or not willing to retaliate against such feedback. However, while DSR makes retaliation more difficult, one might still suspect that by permanently observing the changes of average ratings, a seller might be able to identify the buyer behind a given DSR. This hypothesis is not supported by our data. When the buyer gives an average DSR of 1 but a positive CF, the probability that the seller retaliates upon this with a negative CF is 0.004 , compared to a retaliation probability of 0.468 when the CF is negative. ${ }^{42}$

The experiment suggests that most of the endogenous improvement in performance can be expected from pickier buying. In fact, there is evidence indicating that buyers are indeed more distinguishing under DSR. That is, sellers with a relatively good DSR score have a higher probability of selling listed items after introduction of DSR than the same sellers before introduction of DSR, and sellers with a relatively low DSR have a lower probability of selling with DSR. ${ }^{43}$

\section{Conclusions and challenges for future research}

This study is a first exploration of the market design issues surrounding the engineering of trust and trustworthiness in the marketplace. The study illustrates how gaming in the production of reputation information can significantly hamper the ability of a reputation system to facilitate trust and trade efficiency. Our analysis began with the observation that reciprocity plays a major role in the leaving, timing and content of feedback. While retaliatory feedback is in itself a rather small phenomenon, accounting for less than $1.2 \%$ of the total mutual feedback data (Figure 1), the threat of retaliatory negative feedback distorts feedback in aggregate. The reason is that buyers respond strategically to the threat, either by not reporting bad experiences or waiting for the seller to report first. This, in turn, reduces the informativeness of feedback information, with the end result that a seemingly small phenomenon can substantially hamper trust and market efficiency.

\footnotetext{
42 In support of this observation, straightforward regression analyses show a very high correlation between seller's and buyer's CF, but when controlling for the buyer's CF feedback, correlations with DSR are very low, or even negative.

43 The effects are statistically highly significant, yet, unfortunately, eBay does not allow us to document this data here, because it could theoretically be related to eBay's profits.
} 
A major challenge in solving marketplace trust problems has to do with the need to take account adverse platform effects that may arise from new feedback systems due to side-effects or disruption of path dependencies caused in the migration to a new system. For example, a redesign of a trust system need respect the fact that reciprocity has positive as well as negative consequences for the feedback system. The giving of feedback is largely a public good, and our data suggest that reciprocity is important for getting mutually satisfactory trades recorded. It is therefore desirable that, in mitigating retaliatory feedback, we strive for a targeted approach rather than an approach that attempts to remove all forms of reciprocity. Also, by nature, reputation mechanisms are embedded in repeated games, connecting past with future behavior. It was important to the present redesign to maintain certain aspects of the old system, such as the 3-point (conventional) scoring, so that the information collected prior to the change in the system still be useful in evaluating traders after the changeover, without causing undue confusion.

Our study shows that reciprocal feedback behavior can be channeled, and in a targeted way. The way feedback information is navigated through the system affects whether and how reciprocity influences the candor of feedback. The data show that, compared to a simple open system, both blindness in conventional feedback giving and one-sidedness in a detailed seller rating system increase the information contained in the feedback presented to buyers. As a result, the redesigns likely yield more trust and efficiency in the market, at least in the short-run period that we studied. Additional studies, particularly of longer term effects, should yield further insights.

The laboratory and field data, along with our simple modeling approach, made for a coherent picture of the effects of institutional changes. However, it is the interaction of complementary lab and field data that allows us to be confident in our judgment about the importance of institutional changes. If we only had field data, it would be difficult to unambiguously establish causalities, because both cross- and within platform comparisons do not hold the whole relevant environment constant so that confounding explanations for changes in behavior may arise. While the laboratory experiments cannot capture the various complexities of the corresponding field environments, they demonstrate (beyond their benefits as a test-bed for competing designs) that the interaction of institutions and reciprocity is sufficient to cause the robust empirical patterns observed in the various data sets. This suggests that our understanding of the reputation production process might benefit from a more extensive game theoretic investigation, beyond our sketch of a simple model in Section IV.2. Many reputation systems outside of Internet markets are susceptible to retaliation 
from those given a bad rating, and so we suspect that these patterns are also not unusual in nonelectronic interactions.

EBay introduced 'detailed seller ratings' in March and May 2007. Relative to the conventional feedback on eBay, this feedback is more detailed, one-sided and anonymous. As predicted, the change did not much affect conventional feedback giving, but many traders use the new system to avoid retaliation. This contributes to more reputation dispersion and so improved informativeness. Future studies determining the extent to which the individual components of feedback ratings (detailed, one-sided and anonymous) are a matter of some importance for the efficient application to other Internet and offline market feedback systems.

Naturally, market platforms like eBay have to continuously monitor and improve trust and trustworthiness on their platform. Motivated by the positive effects of detailed seller ratings, eBay moved ahead and introduced further changes in spring 2008. The most important feature of this recent change is that sellers are not allowed to submit negative or neutral feedback anymore, only positive. Basically, this is a move to a one-sided feedback system, as found on many business-toconsumer platforms, but still allows for positive reciprocity. Further research will be devoted to how this new change affects the content, timing, and informativeness of feedback. For example, one might expect that, contrary to their behavior in the previous design, more sellers will move first in feedback giving to trigger positive reciprocity.

\section{References}

Akerlof, G. (1970), The market for lemons: Quality uncertainty and the market mechanism, Quarterly Journal of Economics 84, 488-500.

Ariely, D., A. Ockenfels, and A. E. Roth (2005), An Experimental Analysis of Ending Rules in Internet Auctions, The RAND Journal of Economics 36, 790-809.

Ba, S. and P. Pavlou (2002), Evidence of the Effect of Trust Building Technology in Electronic Markets: Price Premiums and Buyer Behavior, MIS Quarterly 26 (3) 243-268.

Bajari, P. and A. Hortaçsu (2003), The Winner's Curse, Reserve prices and Endogenous Entry: Empirical Insights from eBay Auctions, Rand Journal of Economics 34 (2), 329-355.

Bajari, P. and A. Hortaçsu (2004), Economic Insights from Internet Auctions, Journal of Economic Literature 42 (2), 457-486.

Bolton, G., B. Greiner, and A. Ockenfels (2009), The Effectiveness of Asymmetric Feedback Systems on EBay. Mimeo.

Bolton, G., E. Katok, and A. Ockenfels (2004), How Effective are Online Reputation Mechanisms? An Experimental Study, Management Science 50 (11), 1587-1602. 
Bolton, G., E. Katok, and A. Ockenfels (2005), Cooperation among Strangers with Limited Information about Reputation, Journal of Public Economics 89, 1457-1468.

Bolton, G. and A. Ockenfels (2008), Does Laboratory Trading Mirror Behavior in Real World Markets? Fair Bargaining and Competitive Bidding on Ebay. Working paper, University of Cologne.

Bolton, G. and A. Ockenfels (forthcoming), The Limits of Trust, in: Chris Snijders (Ed.) Trust and Reputation, Russell Sage.

Brandts, J. and N. Figueras (2003), An Exploration of Reputation Formation in Experimental Games. Journal of Economic Behavior and Organization 50, 89-115.

Bretz, R. D., G. T. Milkovich, and W. Read (1992). The Current State of Performance Appraisal Research and Practice: Concerns, Directions, and Implications. Journal of Management 18(2): 321-352.

Brunner, C., J. K. Goeree, C. A. Holt, and J. O. Ledyard (forthcoming), An Experimental Test of Combinatorial FCC Spectrum Auctions, American Economic Journal: Microeconomics.

Cabral, L. and A. Hortaçsu (forthcoming), The Dynamics of Seller Reputation: Theory and Evidence from eBay, Journal of Industrial Economics.

Camerer, C. F. (2003), Behavioral Game Theory, Princeton: Princeton University Press.

Camerer, C. F. and K. Weigelt (1988), Experimental Tests of a Sequential Equilibrium Reputation Model, Econometrica 56, 1-36.

Chen, K. (2005), An Economics Wind Tunnel: The Science of Business Engineering, in John Morgan (ed.), Experimental and Behavioral Economics - Advances in Applied Microeconomics, Volume 13, Elsevier Press, 2005.

Chen, Y. and T. Sönmez (2006), School choice: An experimental study, Journal of Economic Theory 127, 202-231.

Chwelos, P. and T. Dhar (2007), Differences in "Truthiness" across Online Reputation Mechanisms, Working Paper, Sauder School of Business.

Cooper, D. and J. Kagel (forthcoming), Other-regarding preferences, in: J. Kagel and A. Roth (eds.), The Handbook of Experimental Economics, Volume 2, in preparation.

Dellarocas, C. (2004), Building Trust On-Line: The Design of Robust Reputation Mechanisms for Online Trading Communities, in: G. Doukidis, N. Mylonopoulos, N. Pouloudi (eds.), Social and Economic Transformation in the Digital Era, Idea Group Publishing, Hershey, PA.

Dellarocas, C. (2006), Reputation Mechanisms, in:Hendershott, T. (ed.), Handbook on Economics and Information Systems, Elsevier Publishing, 629-660.

Dellarocas, C. and C. A. Wood (2008), The Sound of Silence in Online Feedback: Estimating Trading Risks in the Presence of Reporting Bias, Management Science 54(3), 460-476.

Dewan, S. and V. Hsu (2001), Trust in Electronic Markets: Price Discovery in Generalist Versus Specialty Online Auctions, mimeo.

Eaton, D. H. (2007), The Impact of Reputation Timing and Source on Auction Outcomes, The B.E. Journal of Economic Analysis \& Policy 7(1), Article 33.

Ederington, L. H. and M. Dewally (2006), Reputation, Certification, Warranties, and Information as Remedies for Seller-Buyer Information Asymmetries: Lessons from the Online Comic Book Market, Journal of Business 79, 693-729.

Fehr, E. and S. Gächter (2000), Fairness and Retaliation: The Economics of Reciprocity, Journal of Economic Perspectives 14(3), 159-181. 
Greif, A. (1989), Reputation and Coalitions in Medieval Trade: Evidence on the Maghribi Traders, Journal of Economic History 49(4), 857-882.

Greiner, B. (2004), An Online Recruitment System for Economic Experiments, in: Kurt Kremer, Volker Macho (eds.): Forschung und wissenschaftliches Rechnen 2003. GWDG Bericht 63, Göttingen: Ges. für Wiss. Datenverarbeitung, 79-93.

Grether, D. M., R. M. Isaac, and C. R. Plott (1981), The Allocation of Landing Rights by Unanimity among Competitors, American Economic Review 71(2), 166-171.

Güth , W., F. Mengel, and A. Ockenfels (2007), An Evolutionary Analysis of Buyer Insurance and Seller Reputation in Online Markets, Theory and Decision 63, 265-282.

Hortaçsu, Ali, F. Asís Martínez-Jerez, and Jason Douglas (2009), The Geography of Trade in Online Transactions: Evidence from eBay and MercadoLibre, American Economic Journal: Microeconomics 1(1), 53-74.

Houser, D. and J. Wooders (2005), Reputation in Auctions: Theory and Evidence from eBay, Journal of Economics and Management Strategy 15 (2), 353-369.

Jin, G.Z. and A. Kato (forthcoming). "Price, Quality and Reputation: Evidence from an Online Field Experiment." RAND Journal of Economics.

Kagel, J. H. and A. E. Roth (2000), The Dynamics of Reorganization in Matching Markets: A Laboratory Experiment Motivated by a Natural Experiment, Quarterly Journal of Economics 115(1), 201-235

Kalyanam, K. and S. McIntyre (2001), Returns to Reputation in Online Auction markets, Retail Workbench Working Paper W-RW01-02, Santa Clara University, Santa Clara, CA.

Klein, T. J., C. Lambertz, G. Spagnolo, and K. O. Stahl (2007), Reputation Building in Anonymous Markets: Evidence from eBay, Working Paper, University of Mannheim.

Kreps, D. M. and R. Wilson (1982), Reputation and Imperfect Information, Journal of Economic Theory 27, 253-279.

Kwasnica, A. M., J. O. Ledyard, D. Porter, and C. DeMartini (2005), A New and Improved Design for Multiobject Iterative Auctions, Management Science 51(3), 419-434.

Livingston, J. A. (2005), How Valuable is a Good Reputation? A Sample Selection Model of Internet Auctions, Review of Economics and Statistics 87 (3), 453-465.

Livingston, J. A. and W. N. Evans (2004), Do Bidders in Internet Auctions Trust Sellers? A Structural Model of Bidder Behavior on eBay, Working Paper, Bentley College.

Lucking-Reiley, D., D. Bryan, N. Prasad, and D. Reeves (2007), Pennies from eBay: the Determinants of Price in Online Auctions, Journal of Industrial Economics 55(2), 223-233.

McDonald, C. G. and V. C. Slawson, Jr. (2002), Reputation in an Internet Auction Market, Economic Inquiry 40 (3), 633-650.

Melnik, M. I. and J. Alm (2002), Does a Seller's Reputation Matter? Evidence from eBay Auctions, Journal of Industrial Economics 50 (3), 337-349.

Milgrom, P. (2004), Putting Auction Theory to Work, Cambridge University Press.

Milgrom, P., D. North, and B. Weingast (1990), The Role of Institutions in the Revival of Trade:

The Medieval Law Merchant, Economics and Politics 2, 1-23.

Muniz, J., E. Garcia-Cueto, and L. M. Lozano (2005), Item formation and the psychometric properties of the Eysenck Personality Questionnaire, Personality and Individual Differences 38, 61-69.

Neral, J. and J. Ochs (1992), The Sequential Equilibrium Theory of Reputation Building: A Further Test, Econometrica 60(5), 1151-1169. 
Niederle, M. and A. E. Roth (2009), Market Culture: How Rules Governing Exploding Offers Affect Market Performance, American Economic Journal: Microeconomics 1 (2), forthcoming.

Nunnally, J. C. (1978), Psychometric theory (2nd ed.), McGraw-Hill: New York.

Ockenfels, A. (2003), Reputationsmechanismen auf Internet-Marktplattformen: Theorie und Empirie, Zeitschrift für Betriebswirtschaft 73 (3), 295-315.

Ockenfels, A., D. Reiley, and A. Sadrieh (2006), Online Auctions, in: Terrence J. Hendershott (ed), Handbooks in Information Systems I, Handbook on Economics and Information Systems, 571-628.

Ockenfels, A. and A. E. Roth (2006), Late and Late and multiple bidding in second price Internet auctions: Theory and evidence concerning different rules for ending an auction, Games and Economic Behavior 55, 297-320.

Oppenheim, A.N. (2000), Questionnaire Design, Interviewing and Attitude Measurement, Continuum: London and New York.

Prendergast, C. (1999). The Provision of Incentives in Firms. Journal of Economic Literature 37(1): 7-63.

Prendergast, C. and R. H. Topel (1993). Discretion and Bias in Performance Evaluation. European Economic Review 37(2-3): 355-365.

Reichling, F. (2004), Effects of Reputation Mechanisms on Fraud Prevention in eBay Auctions, Working Paper, Stanford University.

Resnick, P. and R. Zeckhauser (2002), Trust Among Strangers in Internet Transactions: Empirical Analysis of eBay's Reputation System, in: Michael R. Baye (ed.), The Economics of the Internet and E-Commerce (Advances in Applied Microeconomics, Vol. 11), JAI Press.

Resnick, P., R. Zeckhauser, E. Friedman, and K. Kuwabara (2000), Reputation Systems, Communications of the ACM 43 (12), 45-48.

Resnick, P., R. Zeckhauser, J. Swanson, and L. Lockwood (2006), The Value of Reputation on eBay: A Controlled Experiment, Experimental Economics 9, 79-101.

Roth, A. E. (2002), The Economist as Engineer: Game Theory, Experimentation, and Computation as Tools for Design Economics, Fisher-Schultz Lecture, Econometrica 70(4), 1341-1378.

Roth, A. E. (2008), What have we learned from market design?, Hahn Lecture, Economic Journal 118, 285-310.

Roth, A. E. and A. Ockenfels (2002), Last-Minute Bidding and the Rules for Ending Second-Price Auctions: Evidence from eBay and Amazon Auctions on the Internet, American Economic Review 92 (4), 1093-1103.

Selten, R. and R. Stöcker (1986), End behavior in sequences of finite prisoner's dilemma supergames, Journal of Economic Behavior and Organization 7, 47-70.

Wilson, R. (1985), Reputations in Games and Markets, in: A. E. Roth (ed.), Game-Theoretic Models of Bargaining, Cambridge University Press, Cambridge, UK, 27-62. 


\title{
APPENDICES NOT FOR PUBLICATION
}

\author{
Appendix A. Field data sets
}

Summary

Datasets 1 to 3 contain data from eBay. Dataset 1 holds data on one month of transactions on eBay (from six categories in seven countries) and follows their feedback in the old conventional feedback (CF) system. The data also contains individual feedback data from just before and after the change. Dataset 2 mirrors Dataset 1 for the young Feedback 2.0 feedback system (DSR), about 8 months later. Dataset 3 was compiled separately to compare eBay markets with the traditional CF system (like Germany and the U.S.) to existing eBay markets with special institutional variations: the blind MercadoLivre reputation system, and the system used in eBay China, employing different feedback rules for 'verified' and 'unverified' buyers.

Datasets 4 and 5 are compiled from other sources. In Dataset 4 we collected all feedback data left until 2007 on RenACoder.com. Dataset 5 is a snapshot of feedback data on Amazon.de. In the following we provide detailed information on source, retrieval method, and content of our data sets.

A.1 Dataset 1 - eBay transactions in Nov/Dec 2006 and corresponding feedback until March 2007. We constructed a sample involving about one million postings on eBay in November and December 2006. The eBay sites included in our sample were ebay.benl.be, ebay.co.uk, ebay.com.au, ebay.fr, and ebay.pl, where the feedback redesign was introduced in beginning of March 2007, as well as ebay.com and ebay.de, with a starting date of the new system in early May 2007 . We decided for 6 different categories, which represent products traded on eBay with different levels of heterogeneity, prices and average feedback: original printer cartridges (CART), new cell phones without service contract (CELL), fragrances (FRAG), antiques (ANTIQUES), paper money (MONEY) and amazon.(com $\mid$ de $\mid$ co.uk) gift certificates (AMAZ). To obtain transaction ids we conducted searches for all available completed eBay listings in these categories and countries at a specific date (for categories AMAZ, CELL, CART, MONEY in countries co.uk, com, com.au, de, fr, pl on 12/13/2006, for categories ANTIQUES and FRAG and country be on 12/23/2006). Then we downloaded the auction main pages for all these item ids from the respective country's eBay website, and the bid/purchase history pages from eBay.com, where appropriate. Auction and bid pages were parsed for all available information. In the second half of May 2007 we downloaded the feedback profiles for all sellers and successful buyers at least back to the date of the first eBay listing in our sample they were involved in. If feedback profiles were invalid or set to private, we additionally downloaded the feedback giving profiles of their transaction partners. From the feedback data, we extracted the feedback aggregates (feedback score, \%pos, number of feedbacks received, detailed seller ratings if existent, etc.) at the time of download as well as all individual feedbacks (feedback, time, item id, partner, comment, etc.) received/given between the end of listing and the feedback download. Using feedback profiles at download time and individual feedbacks received since listing end time, we reconstructed the feedback score and the percentage of positive feedbacks of seller and buyer(s) of each item at the listing end time. Furthermore, for each successful eBay transaction in our sample, we searched for the feedback value and times given by the transaction partners to each other. Altogether we were able to identify detailed feedback behavior for more than $99.8 \%$ of successful transactions in our sample. Table 8 provides descriptive statistics of our dataset. 
TABLE 8: DESCRIPTIVES OF DATASET 1

\begin{tabular}{|c|c|c|c|c|c|c|c|c|c|c|c|c|c|c|c|}
\hline & \multirow[b]{2}{*}{$\mathbf{N}$} & \multicolumn{5}{|c|}{ Feedback and timing } & \multicolumn{5}{|c|}{ Buyer's feedback } & \multicolumn{4}{|c|}{ Seller's feedback } \\
\hline & & $\begin{array}{l}\text { No } \\
\text { FB }\end{array}$ & $\begin{array}{c}\text { Onl } \\
\mathbf{y} \\
\mathbf{B}\end{array}$ & $\begin{array}{c}\text { Only } \\
\text { S }\end{array}$ & $\begin{array}{c}\text { B } \\
\text { first }\end{array}$ & $\begin{array}{c}\text { S } \\
\text { first }\end{array}$ & + & 0 & - & $\begin{array}{c}\text { B } \\
\text { wd }\end{array}$ & $\begin{array}{l}\text { mut } \\
\text { wd }\end{array}$ & + & 0 & - & $\begin{array}{c}\mathrm{mu} \\
\mathrm{t} \\
\mathrm{wd}\end{array}$ \\
\hline All & 722,929 & 23.5 & 6.5 & 6.5 & 44.2 & 19.4 & 97.1 & 1.0 & 1.4 & 0.3 & 0.2 & 97.9 & 0.2 & 1.6 & 0.2 \\
\hline \multicolumn{16}{|l|}{ Country } \\
\hline Belgium & 12,293 & 19.0 & 4.9 & 6.9 & 43.9 & 25.3 & 96.9 & 0.9 & 1.6 & 0.4 & 0.2 & 97.5 & 0.4 & 1.9 & 0.2 \\
\hline U.K. & 143,794 & 22.4 & 6.2 & 6.4 & 43.2 & 21.8 & 97.5 & 0.8 & 1.3 & 0.2 & 0.2 & 97.4 & 0.2 & 2.2 & 0.2 \\
\hline U.S. & 302,140 & 27.9 & 6.6 & 7.0 & 43.5 & 15.0 & 96.6 & 1.2 & 1.5 & 0.4 & 0.3 & 97.8 & 0.2 & 1.7 & 0.3 \\
\hline Australia & 31,978 & 24.1 & 4.6 & 5.6 & 46.7 & 18.9 & 97.4 & 0.9 & 1.2 & 0.3 & 0.2 & 97.9 & 0.2 & 1.7 & 0.2 \\
\hline Germany & 192,502 & 17.3 & 6.9 & 6.0 & 45.9 & 23.9 & 97.5 & 0.9 & 1.2 & 0.3 & 0.1 & 98.7 & 0.2 & 0.9 & 0.1 \\
\hline France & 39,088 & 23.5 & 6.4 & 6.0 & 43.3 & 20.8 & 95.9 & 1.4 & 2.0 & 0.4 & 0.3 & 96.5 & 0.5 & 2.7 & 0.3 \\
\hline Poland & 1,134 & 48.9 & 5.6 & 5.2 & 25.2 & 15.2 & 96.9 & 0.4 & 2.1 & 0.6 & 0.0 & 97.5 & 0.0 & 2.5 & 0.0 \\
\hline \multicolumn{16}{|l|}{ Category } \\
\hline Amaz & 842 & 12.8 & 10.0 & 9.4 & 38.2 & 29.6 & 99.1 & 0.0 & 0.3 & 0.6 & 0.0 & 98.9 & 0.0 & 1.1 & 0.0 \\
\hline Antiques & 47,052 & 19.9 & 5.6 & 7.0 & 45.7 & 21.8 & 98.3 & 0.7 & 0.7 & 0.2 & 0.1 & 98.8 & 0.2 & 0.9 & 0.1 \\
\hline Cart & 16,450 & 11.5 & 6.0 & 6.3 & 45.4 & 30.8 & 98.8 & 0.5 & 0.6 & 0.1 & 0.0 & 99.6 & 0.1 & 0.3 & 0.0 \\
\hline Cell & 363,735 & 29.5 & 6.6 & 7.5 & 38.4 & 17.8 & 95.4 & 1.5 & 2.2 & 0.6 & 0.3 & 96.7 & 0.3 & 2.7 & 0.3 \\
\hline Frag & 270,798 & 17.9 & 6.6 & 4.9 & 51.8 & 18.7 & 98.3 & 0.7 & 0.8 & 0.2 & 0.1 & 98.9 & 0.2 & 0.8 & 0.1 \\
\hline Money & 24,052 & 10.6 & 4.4 & 7.0 & 41.5 & 36.5 & 99.5 & 0.1 & 0.2 & 0.2 & 0.0 & 99.7 & 0.0 & 0.2 & 0.0 \\
\hline
\end{tabular}

Notes: All shares in \%. "No FB" stands for no feedback, "Only B/S" for feedback given only by buyer/seller, "B/S first" for feedback given by both, but buyer/seller first, +/0/- for positive/neutral/negative feedback, respectively. 'B wd' denotes buyer feedback withdrawn by eBay, and 'mut wd' means feedback mutually withdrawn by transaction partners.

Individual eBay feedbacks until May 2007. In order to create Dataset 1 we downloaded the feedback profiles of the about 1 million involved eBay members back to the page of their feedback profile covering the time of the first listing in our sample they were involved in. Profiles were downloaded in pages with 200 individual feedbacks each. All these feedback profiles were parsed for individual feedbacks, not necessarily directly connected to the transactions in Dataset 1 . The same was done for the obtained feedback giving profiles. Over all included countries, this procedure resulted in 78,045,630 individual feedbacks before the introduction of Feedback 2.0 in March/May 2007, and about 7,060,819 individual feedbacks thereafter until May 2007, which allow us to track short-term changes in CF feedback and early DSR feedback scores.

A.2 Dataset 2 - eBay transactions between June $1^{\text {st }}$ and June $14^{\text {th }} 2007$ and corresponding feedback under Feedback, 2.0 until September 2007. This dataset was assembled in conjunction with eBay, and mirrors Dataset 1 for the post-Feedback 2.0 period. For the same categories and countries as in Dataset 1 , the data set includes transaction and feedback information for successful transactions which have taken place in the two weeks between 06/01/2007 until 06/14/2007. (The only category mistakenly not included was "printer cartridges" in France.) Some categories were defined somewhat broader (for example, "gift certificates" instead of "amazon gift certificates"). Altogether, the set includes data from completed 573,567 transactions and 963,925 individual feedbacks. All eBay user names were anonymized in the data, which also did not include any personal information. Besides the transaction and feedback details the data set includes the individual detailed seller ratings given by buyers, which would not be available in a downloaded dataset. In order to protect eBay's commercial interests, we are not able to report this data in such detail as for the downloaded Dataset 1.

A.3 Dataset 3 - Feedback data from Mercado Livre, eBay China, and other eBay sites from June 2006. Between June $12^{\text {th }}$ and June $26^{\text {th }} 2006$ we elicited all offers in categories Antiques/Art, Cell phones, and Health\&Beauty from eBay's platforms in the 
U.S., Germany, and China, as well as from the eBay-owned platform in Brazil, which is called Mercado Livre and active throughout South America. Of these listings, we selected random samples of $2 \%, 6 \%$, and $20 \%$ for U.S., Germany, and China, respectively, and included all listings in Brazil. From these we excluded observations involving eBay members with "private" eBay profiles, for which feedback data could not be elicited. This procedure left us with 28,435 completed transactions. Table 9 shows a summary of observations.

\section{TABLE 9: DESCRIPTIVES OF DATASET 3}

\begin{tabular}{|c|c|c|c|c|}
\hline \multicolumn{5}{|c|}{ Number of observations } \\
\hline & Transactions & Buyer gives FB & Seller gives FB & Both give FB \\
\hline US & 10,169 & 7,602 & 7,799 & 6,941 \\
\hline Germany & 14,297 & 11,052 & 10,990 & 10,070 \\
\hline China & 2,011 & 188 & 178 & 125 \\
\hline B unverified & 949 & 29 & 34 & 15 \\
\hline B verified & 1,062 & 159 & 144 & 110 \\
\hline Brazil & 1,958 & 1,394 & 1,721 & 1,276 \\
\hline \multicolumn{5}{|c|}{ Buyer gives feedback ... } \\
\hline & Positive & Neutral & negative & withdrawn \\
\hline US & 7,492 & 42 & 48 & 20 \\
\hline Germany & 10,847 & 73 & 91 & 41 \\
\hline China & 151 & 1 & 5 & 2 \\
\hline$B$ unverified & & & & \\
\hline B verified & 151 & 1 & 5 & 2 \\
\hline Brazil & 1,134 & 172 & 88 & \\
\hline \multicolumn{5}{|c|}{ Seller gives feedback ... } \\
\hline & Positive & Neutral & negative & withdrawn \\
\hline US & 7,704 & 14 & 74 & 7 \\
\hline Germany & 10,872 & 20 & 83 & 15 \\
\hline China & 166 & 2 & 10 & 0 \\
\hline B unverified & 29 & 0 & 5 & 0 \\
\hline B verified & 137 & 2 & 5 & 0 \\
\hline Brazil & 1,218 & 214 & 289 & \\
\hline
\end{tabular}

A.4 Dataset 4 - Feedback data from RentACoder.com. On RentACoder.com, buyers and sellers (coders) can give feedback on a 10-point scale, along with verbal comments. In March 2007, we downloaded feedback data from all 192,392 transactions which took place between January 2004 and January 2007. In addition to feedback submitted by transaction partners, an arbitrator from RentACoder.com gives comments in cases where projects were not completed. We ignored those observations in our dataset.

A.5 Dataset 5 - Feedback data from Amazon.de and survey with Amazon sellers. In May 2007 we downloaded feedback data of 10,474 Amazon.de marketplace sellers from the Amazon.de website. Amazon's application programming interface (API) allows to request only up to 50 recent feedbacks per seller. We started with all sellers who offered the German version of the then popular book "Vanish" by Tess Gerritsen. The book was chosen as it was on Amazon's bestseller list and was offered by many different sellers. From these sellers we downloaded details of the 50 last feedbacks, including the item ids of the products they have sold. For each of these item ids, we downloaded the 50 recent feedbacks of all sellers who currently offered this product on Amazon.com. We repeated this process until the number of captured Amazon sellers hit the threshold of 10,000. Our resulting data set consists of 320,609 feedbacks given by buyers to sellers.

Note that the API's restriction of 50 feedbacks per seller results in an overweighting of feedback from smaller sellers in our data set compared to the total amount of individual feedbacks on Amazon, but yields a representative picture of the performance of the average seller in recent transactions. To obtain some data on feedback frequencies and feedback system perceptions, in June 2007 we contacted a random sample of 590 Amazon sellers in our data set using the Amazon contact form, and asked them to answer three questions on frequency of buyer feedback, satisfaction with 
buyer feedback, and desirability of a two-sided system. 91 of the contacted sellers responded to our survey, with an average of 778 received feedbacks on Amazon (ranging from 1 to 10,699).

\section{Appendix B. Laboratory experiment instructions}

Welcome and thank you for participating in this experiment. In this experiment you can earn money. The specific amount depends on your decisions and the decisions of other participants. From now on until the end of the experiment, please do not communicate with other participants. If you have any questions, please raise your hand. An experimenter will come to your place and answer your question privately. In the experiment we use ECU (Experimental Currency Unit) as the monetary unit. 200 ECUs are worth 1 Euro.

At the beginning of the experiment all participants are endowed with an amount of 1000 ECU. Profits during the experiment will be added to this account, losses will be deducted. At the end of the experiment, the balance of the account will be converted from ECUs into Euros according to the conversion rate announced above, and paid out in cash.

The experiment lasts for 60 rounds. In each round, participants will be matched into groups of four participants. One of these participants is the seller, the other three participants are buyers. The composition of the group, and in which rounds you are a seller and in which rounds you are a buyer will be randomly determined by the computer. The seller offers one good which, if produced in $100 \%$ quality, costs him 100 ECUs to produce. Each of the potential buyers is assigned a valuation for the good, which lies between 100 and 300 ECUs. The valuation represents the value of the good for the buyer if he receives it in 100\% quality (more about quality will be said below). The valuations of the three buyers will be newly randomly drawn in each round. When drawing a valuation, every integer value between 100 and 300 has the same probability to be selected.

Each round consists of three steps: in the "auction stage" the three potential buyers may bid for the item offered by the seller. In the "transaction stage" the seller receives the price which has to be paid by the auction winner, and decides about the quality of the good he will deliver. In the "feedback stage" both buyer and seller may give feedback on the transaction, which is then made available to traders in later rounds. In the following we explain the procedures of the three stages in detail.

Auction stage. In the first stage in each round, each of the potential buyers may submit a maximum bid for the good:

1. Your maximum bid is the maximum amount you'd be willing to pay for winning the auction. If you do not want to participate in the auction, submit a maximum bid of 0 . If you want to participate, submit a maximum bid of at least 100 ECUs, which is the minimum price. (Your maximum bid must not exceed the current amount on your account.)

2. The bidder who submits the highest maximum bid wins the auction. The price is equal to the second highest bid plus $1 \mathrm{ECU}$. Exceptions: The price is equal to $100 \mathrm{ECU}$ if only one potential buyer submits a bid. The price is equal to the maximum bid of the auction winner, if the two highest maximum bids are the same (in this case, the bidder who has submitted his bid first wins the auction).

3. You may think of the bidding system as standing in for you as a bidder at a live auction. That is, the system places bids for you up to your maximum bid, but using only as much of your bid as is necessary to maintain your highest bid position. For this reason, the price cannot exceed the second highest bid plus 1 ECU.

The winner of the auction must pay the price to the seller and proceeds to the transaction stage. All other potential buyers earn an income of $0 \mathrm{ECU}$ in this round.

Transaction stage. The seller receives the price and then determines the quality of the good. The quality must be between $0 \%$ and $100 \%$. Each quality percent costs the seller 1 ECU. Thus, the costs for the seller for selling the good are 0 ECU if the quality is $0 \%$, and $100 \mathrm{ECU}$ if the quality is $100 \%$. The value of the good for the buyer who has won the auction equals the quality of the good times his valuation for the good. Thus the value of the good for the buyer is 0 ECU if the quality is $0 \%$, and equal to his valuation if the quality is $100 \%$.

In equations:

The payoff for the Seller in this round equals: Auction price - Quality [\%]* 100

The payoff for the auction winner in this round is: Quality [\%]* Valuation - Auction price 


\section{Feedback stage}

Baseline \{The feedback stage consists of one or two steps: After the transaction both the buyer and the seller decide whether or not they want to submit a feedback on the transaction. Submitting a feedback costs 1 ECU. The feedback can be either "negative", "neutral", or "positive". If both transaction partners submit feedback, or none of them submits feedback, then the feedback stage ends at this point.

If only one transaction partner submits feedback, then the other transaction partner is informed about this feedback. The transaction partner who has not submitted feedback yet has another chance to submit feedback. Again, submitting feedback costs 1 ECU, and the feedback can be either "negative", "neutral", or "positive".

After the feedback stage the round ends. If a participant becomes a seller in one of the following rounds, the feedbacks he received in earlier rounds as a buyer or a seller will be presented in the following way: "YY (XX\%)", where YY is equal to the number of positive feedbacks minus the number of negative feedbacks, and XX is the share (in percent) of positive feedbacks in all feedbacks. $\}$

Blind A After the transaction both the buyer and the seller decide whether or not they want to submit a feedback on the transaction. Submitting a feedback costs 1 ECU. The feedback can be either "negative", "neutral", or "positive". The feedback giving of buyer and seller takes place simultaneously.

After the feedback stage the round ends. If a participant becomes a seller in one of the following rounds, the feedbacks he received in earlier rounds as a buyer or a seller will be presented in the following way: "YY (XX\%)", where YY is equal to the number of positive feedbacks minus the number of negative feedbacks, and XX is the share (in percent) of positive feedbacks in all feedbacks.\}

DSR: \{ The feedback stage consists of one or two steps: After the transaction both the buyer and the seller decide whether or not they want to submit a feedback on the transaction. Submitting a feedback costs 1 ECU. The feedback can be either "negative", "neutral", or "positive". Additionally, the buyer (and only the buyer) may submit an additional rating. (This is only possible if he also submits a normal feedback. The additional rating allows the buyer to give feedback on the following scale:

\section{The quality was satisfactory.}

I strongly disagree I disagree Undecided I agree I strongly agree

There are no additional costs for the additional rating. If both transaction partners submit feedback, or none of them submits feedback, then the feedback stage ends at this point. If only one transaction partner submits feedback, then the other transaction partner is informed about the "negative"/"neutral"/"positive" feedback; but the seller is not informed about the content of the additional rating submitted by the buyer. The transaction partner who has not submitted feedback yet has another chance to submit feedback. Again, submitting feedback costs 1 ECU, and the feedback can be either "negative", "neutral”, or "positive".

After the feedback stage the round ends. If a participant becomes a seller in one of the following rounds, the feedbacks he received in earlier rounds as a buyer or a seller will be presented in the following way: "YY (XX\%)", where YY is equal to the number of positive feedbacks minus the number of negative feedbacks, and XX is the share (in percent) of positive feedbacks in all feedbacks. The additional ratings which a participant received as a seller in earlier rounds will be presented in the following form: "on average X.X, based on XXX additional ratings".\}

Before you start with the experiment you will take part in two trial rounds. In the first trial round you are a buyer, in the second trial round you are a seller. The other buyers/the seller will be simulated by the computer in these trial rounds. The trial rounds have no consequences for your earnings. 


\section{Appendix C. Additional tables and figures}

Table 10: Determinants of Feedback giving, Probit CoefFicient Estimates (ROBUST STANDARD ERRORS CLUSTERED ON MATCHING GROUP, ROUNDS 1 TO 50)

\begin{tabular}{|c|c|c|}
\hline \multirow[t]{2}{*}{ Dep var } & \multicolumn{2}{|c|}{ Buyer gave feedback } \\
\hline & Coeff & (StdErr) \\
\hline Constant & $1.50 * * *$ & $(0.227)$ \\
\hline Blind & $-0.296 * *$ & $(0.131)$ \\
\hline DSR & 0.012 & $(0.157)$ \\
\hline Round & $-0.008 * *$ & $(0.004)$ \\
\hline Price & -0.001 & (0.001) \\
\hline Quality & $-0.006 * * *$ & $(0.002)$ \\
\hline S FScore & $0.120 *$ & $(0.011)$ \\
\hline $\mathrm{N}$ & \multicolumn{2}{|c|}{2283} \\
\hline Restricted LL & \multicolumn{2}{|c|}{-1226.2} \\
\hline
\end{tabular}

Note: *,**, and $* * *$ indicate significance at the $10 \%, 5 \%$ and $1 \%$ level, respectively. S FScore stands for the feedback score of the seller.

TABLE 11: CONTENT AND TIMING OF MUTUAL FEEDBACK IN EXPERIMENTAL BASELINE TREATMENT

\begin{tabular}{cccc}
\hline \hline \multicolumn{4}{c}{ Mutually positive feedback } \\
\hline & \multicolumn{3}{c}{ Seller gave in stage } \\
& 1 & 2 \\
\hline Buyer gave & 1 & 137 & 79 \\
in stage & 2 & 16 &
\end{tabular}

Only buyer gave problematic FB

\begin{tabular}{cccc}
\hline & \multicolumn{3}{c}{ Seller gave in stage } \\
& & 1 & 2 \\
\hline Buyer gave & 1 & 59 & 3 \\
in stage & 2 & 11 & \\
\hline
\end{tabular}

\begin{tabular}{cccc}
\multicolumn{3}{c}{ Only seller gave problematic FB } \\
\hline & \multicolumn{2}{c}{$\begin{array}{c}\text { Seller gave in stage } \\
1\end{array}$} & 2 \\
\hline Buyer gave & 1 & 7 & 6 \\
in stage & 2 & &
\end{tabular}

Mutually problematic feedback

\begin{tabular}{crrc}
\hline & \multicolumn{2}{c}{ Seller gave in stage } \\
& & 1 & 2 \\
\hline Buyer gave & 1 & 24 & 108 \\
in stage & 2 & 8 & \\
\hline
\end{tabular}

$\overline{\text { Note: Numbers in cells represent absolute numbers of observations in treatment Baseline. }}$ 'Problematic' includes negative and neutral feedback. 
FIGURE 8: SCREENSHOT OF NEW FEEDBACK SUBMISSION PAGE ON EBAY

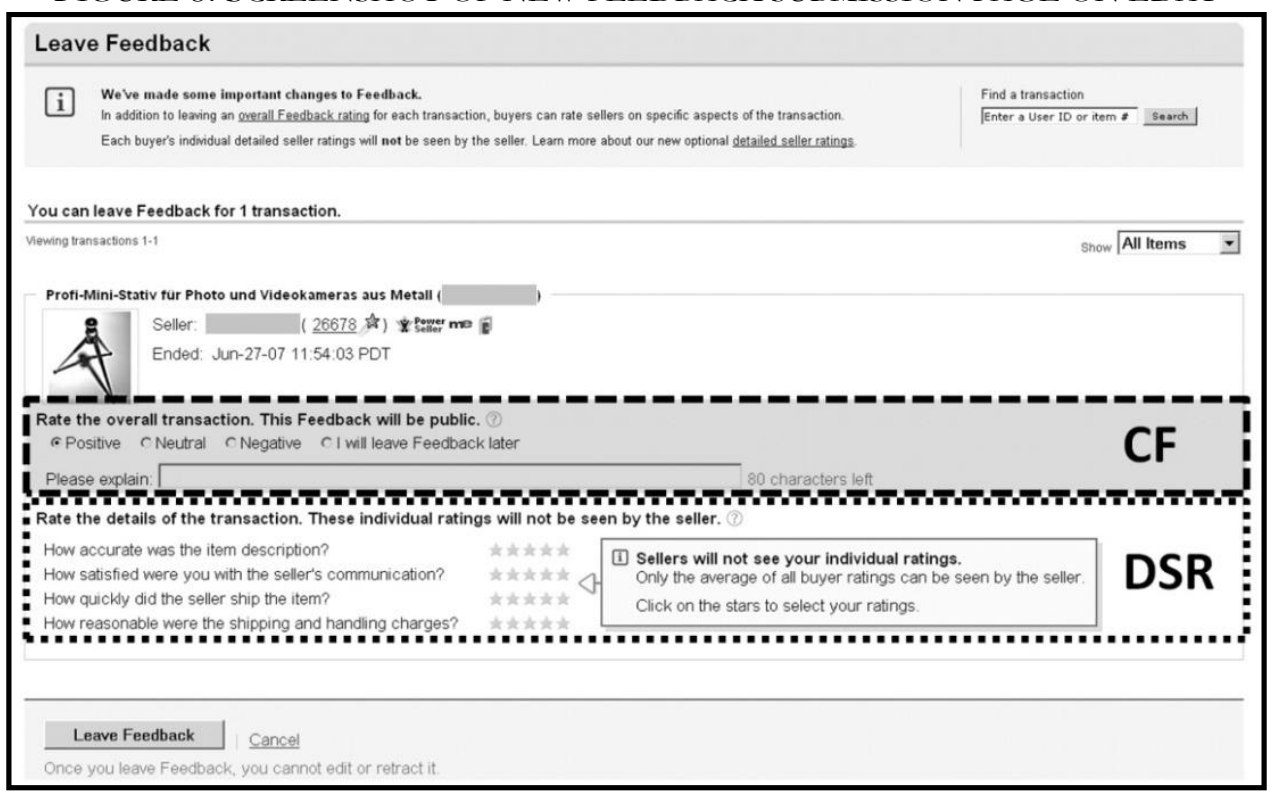

FIGURE 9: SCREENSHOT OF NEW FEEDBACK PROFILE PAGE ON EBAY

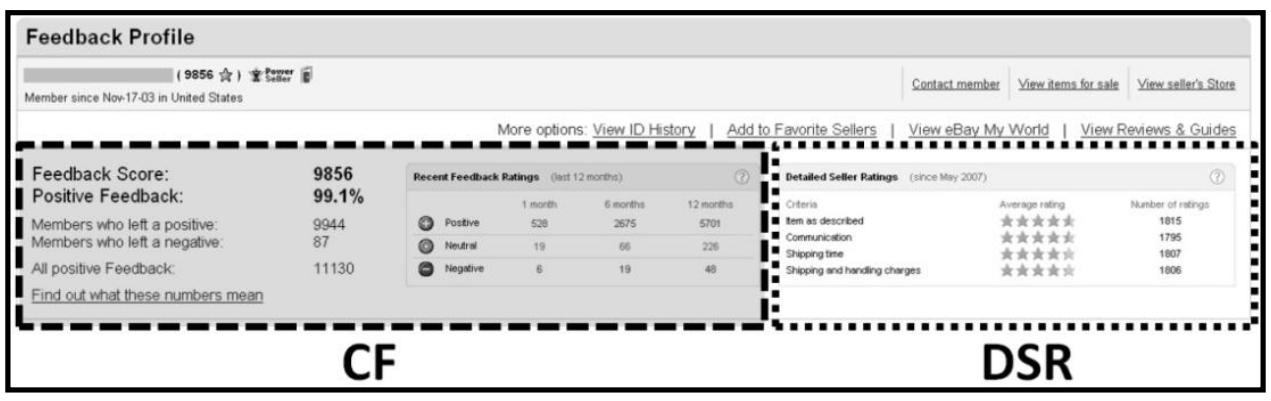

